\title{
LA ADQUISICIÓN DEL TESORO EN ÉPOCA CLÁSICA EN DERECHO ROMANO
}

\author{
Alfonso AGUDo RUIZ \\ CATEDRÁTICO DE DERECHO ROMANO \\ UNIVERSIDAD DE LA RIOJA
}

SUMARIO: I. Las pretensiones fiscales sobre los tesoros. II. La regulación de Adriano. III. Continuidad de la regulación adrianea. IV. La regulación de Marco Aurelio y Lucio Vero. V. La regulación de Alejandro Severo.

RESUMEN: A partir del siglo I d.C. adquiere relevancia jurídica la figura del inventor. Posteriormente, Adriano establece una nueva regulación de la adquisición del tesoro, que se mantiene en lo esencial hasta nuestros días. Los aspectos más sobresalientes de la regulación adrianea son, de un lado, el reconocimiento y la posición de igualdad en que coloca al inventor respecto del dominus loci cuando el descubrimiento del tesoro se produce en fundo ajeno, de otro lado, la equiparación del emperador, del fisco o de la ciudad a cualquier propietario particular en lo que respecta a su derecho sobre los hallazgos. Entre los años i6o y i6r, tiene lugar una extensión de las pretensiones fiscales introducida por Marco Aurelio y Lucio Vero, se amplían a los loca religiosa y a los monumenta, y se aumenta la pena en caso de falta de denuncia al fisco del tesoro descubierto. Alejandro Severo restablecerá las pretensiones fiscales con carácter general, al menos, en lo que respecta a los tesoros más valiosos.

Palabras ClaVE: inventor; dominus loci; Adriano; Marco Aurelio y Lucio Vero; Alejandro Severo.

ABSTRACT: From I century after Christ, the figure of the inventor becomes very important from the juridical point of view. Later, Adrian stablishes a new regulation of the acquisition of the treasure, which continves in the essential aspects at the present time. The more outstanding aspects of the Adrian's regulation are, on the one hand the recognition and the position of equality of the inventor respect to the dominus loci when the finding of the treasure takes place in another estate, and on the other hand, the comparison of the emperor, the treasury or the city to the right of the findings. Between the year I60 and I6I, Marco Aurelio and Lucio Vero carry out an extension of the fiscal claims, extend them to the loca religiosa and the monumenta and they increase the penalty in case of pack of complaint of the discovered treasure to the treasury. Alejandro Severo will generally reestablish the fiscal claims, at least with regard to the more valuable treasures.

KEYWORDS: inventor; dominus loci; Adriano; Marco Aurelio y Lucio Vero; Alejandro Severo. 


\section{Las pretensiones fiscales sobre los tesoros}

En el período correspondiente al tránsito de la República al Principado, aparece una nueva concepción de la adquisición del tesoro bajo el prisma posesorio en la que cobra relevancia el descubrimiento del mismo como tal.

En opinión de Lauria ${ }^{\mathrm{I}}$, una vez que la jurisprudencia niega la posición sostenida por Bruto y Manilio, se plantea la cuestión del tesoro desde un punto de vista posesorio, pero en el que el descubridor gozaba de una situación privilegiada, la posesión se funde y disuelve en valoraciones extrañas, impuestas por la relevancia política del tesoro que es el objeto.

De las Heras ${ }^{2}$ no subscribe totalmente la opinión de Lauria de que el tesoro adquiere autonomía, relevancia propia, ante todo, bajo el perfil posesorio. Considera que sería al contrario, esto es, que la posesión del tesoro adquiere importancia cuando los juristas individualizan el tesoro respecto del fundo. Y comienzan a plantearse la cuestión desde esquemas tradicionales de la possessio: scientia, corpus, animus. Pero, lógicamente, bajo el aspecto posesorio y descartando, como fundamento de la adquisición, la identificación tesoro-fundo, comienza a tener una relevancia especial el descubrimiento, que es lo que realmente vuelve a traer el tesoro a la realidad, a su propia existencia individual, y consecuentemente se reconoce la especial relevancia del descubridor.

D, 4I, 2, 3, 3 (Paulus, LIV ad Edictum): Neratius et Proculus et solo animo non posse non adquirere possessionem, si non antecedat naturalis possession. Ideoque si thensaurum in fundo meo positum sciam continuo me possidere, simul atque possidendi affectum habuero, quia quod desit naturali possessioni, id animus implet. Ceterum quod Brutus et Manilius putant eum, qui fumdum longa possessione cepit, etiam thensaurum cepisse, quamvis nesciat in fundo esse, non est verum: is enim qui nescit non possidet thensaurum quamvis fundum possideat. Sed et si sciat, non capiet longa possession, quia scit alienum esse. Quidam putant Sabini sententiam veriorem esse nec alias eum qui scit possidere, nisi in loco motus sit, quia non sit sub custodia nostra: quibus consentio.

Del texto de Paulo interesa destacar ahora la nueva concepción de la scientia que adoptan Próculo y Neracio, como justificación del rechazo de la opinión de Bruto y Manilio. Observan críticamente que «...is enim qui nescit, non possidet thensaurum, quamvis fundum possideat...». Para Neracio y Próculo el propietario del fundo posee el tesoro que se encuentra en su fundo -in fundo meo positum - en cuanto lo conoce y lo quiera poseer ${ }^{3}-s i$

I LAURIA, «Dal possessore del tesoro all' 'inventor' (D. 4I.2.3.3.)», Labeo. Rassegna di diritto romano, I, I955, pág. 27.

2 DE LAS HERAS, «Adquisición del tesoro en el Fuero de Cuenca: bases romanas y evolución posterior», Actas del II Congreso Internacional y V Iberoamericano de Derecho Romano. Los derechos reales, Madrid, 200I, pág. 67.

${ }^{3}$ La lectura de la parte inicial del texto, en la que se expone la opinión de los Proculianos, ha sido la más discutida por la doctrina que ha considerado que para Neracio y Próculo la posesión puede adquirirse «solo animo», independientemente de la existencia de una situación material. Por el contrario, como ha observado METRO, L'obbligazione di custodire nel diritto romano, Milano, Giuffrè, I966, págs., 62 y ss., Neracio y Próculo se limitan a afirmar que el animus puede dar origen a la posesión, si se añade a una preexistente situación de hecho, sin necesidad de que ésta venga renovada; los Sabinianos, por el contrario, exigen una nueva aprehensión material de la cosa. Desde este punto de vista afirma SCARCELLA, «Una nuova concezione del tesoro alla luce di C. I. IO.I5.I», Atti dell'Accademia peloritana dei Pericolanto. Lasse di scienze giuridiche, economiche e politiche, 58, I989 (I99I), pág. 2I2 nt. 70, que así se comprende porque Neracio y Próculo frente a un tesoro, objeto de adquisición, que se encuentra en el fundo del adquirente, luego en su disponibilidad material, hayan admitido que el animus, al que se añade una ya existente situación de hecho, diese origen a la posesión. 
thensaurum in fundo meo positum sciam continuo me possidere, simul atque possidendi affectum habuero-. Sabino va más lejos -non alias eum qui scit possidere nisi in loco motus sit, quia non sit sub custodia nostra- y exige al descubridor la aprehensión material para adquirir la posesión.

Podemos afirmar con $\mathrm{Maschi}^{4}$ que: a) únicamente el elemento psicológico (animus) no es suficiente para la adquisición de la posesión, si no viene precedido del elemento material (naturalis possessio); b) por ello el conocimiento por parte del propietario del fundo de la existencia del tesoro en el propio fundo, hace que el propietario, que posee el fundo, posea también el tesoro si tiene el animus (simulatque possidendi affectum habuero); c) la voluntad de poseer el tesoro suple la falta de la aprehensión material del mismo que se compensa con la posesión del fundo en el que éste se encuentra; d) de aquí deviene clara la contraposición con el régimen arcaico y la opinión de Bruto y de Manilio. Esos prescinden del animus, conforme a la concepción posesoria de los veteres, y consideran que quien poseeusucape el fundo, viene a poseer-usucapir el tesoro.

A lo largo del siglo I d. C., el tesoro, según Lauria ${ }^{5}$, adquiere autonomía, relevancia propia sobre todo bajo el perfil posesorio. Correlativamente emerge la figura del descubridor, que se presenta con semblante incierto, con perfiles poco claros, y coincidente con la aparición del régimen fiscal sobre los tesoros. Para Scarcella ${ }^{6}$, cuando comienzan a aparecer las pretensiones fiscales, el papel del descubridor cobra importancia, ya que sólo después del descubrimiento el fisco puede hacer valer sus pretensiones.

Constituye una opinión ampliamente difundida en la doctrina romanística que las pretensiones fiscales sobre los tesoros habrían sido afirmadas ya desde principios de la época imperial. Sin embargo, resulta discutida tanto la naturaleza de tales pretensiones, como la proporción de este derecho en el tesoro descubierto.

Sobre la naturaleza de las pretensiones del fisco pueden individualizarse fundamentalmente dos posiciones doctrinales.

La primera posición, defendida por Pampaloni y Rotondi ${ }^{7}$ considera que se aplicaría el principio según el cual los fundos provinciales se consideran propiedad del pueblo romano o del príncipe, por lo que el tesoro pertenecería al erario o al fisco, según se tratase de provincias senatoriales o de provincias imperiales, respectivamente. Añaden que para dar a esta conclusión su justo valor práctico, especialmente con relación al régimen ordinario, es necesario no olvidar que en la época imperial los fundos provinciales representan la casi totalidad del Imperio, por lo que su régimen se constituye en la regla general, frente a la limitada aplicabilidad del ius italicum.

\footnotetext{
${ }^{4} \mathrm{MASCHI}$, «Concezioni antiche e concezione classiche nell'acquisto del tesoro», Il diritto romano, I, Milano, I966, pág. 49I.

${ }^{5}$ LAURIA, «Dal possessore del tesoro all' 'inventor' (D. 4I.2.3.3.)», cit., pág. 27.

${ }^{6}$ SCARCELLA, «Una nuova concezione del tesoro alla luce di C. I. IO.I5.I», cit., pág. 213.

7 PAMPALONI, «Il concetto giuridico del tesoro nel diritto romano e ordierno», Studi giuridici e storici per l' VIII centenario della Università di Bologna, Roma, I888, pág. I07; ROTONDI, «I ritrovamenti archeologici e il regime dell'acquisto del tesoro», Rivista di diritto civile, 2, I9IO, págs., 3I9 y ss.
} 
La segunda posición, por el contrario, cuyo máximo representante es Bonfante ${ }^{8}$, y que constituye la opinión mayoritaria, considera acertadamente que el derecho del fisco sobre los tesoros encuentra su origen en el régimen de los bona vacantia establecido por la lex Iulia de Augusto.

La analogía entre la situación de los bona vacantia y aquella del tesoro ha sido debidamente subrayada por Provera'. Para este autor, si la hipótesis de Bonfante es cierta, la adquisición por descubrimiento podría justificarse históricamente vinculándola a las disposiciones de la lex Papia, que atribuye a los delatores el derecho a un premio (probablemente de la mitad de los bienes denunciados), por la actividad desarrollada en defensa de los derechos del aerarium. En apoyo de su tesis, Provera cita un texto de Calistrato (D. 49, I4, 3, Io) del que se desprende, con seguridad, que la esfera de aplicación originaria de la vindicatio caducorum fue extendida para admitir que un quivis de populo pudiera reivindicar la parte del tesoro correspondiente al fisco ope legis. La expresión usada por Calistrato «fisco vindicari», la misma utilizada para los caduca y los vacantia, tiene un preciso significado técnico: los bienes que constituyen el tesoro se encuentran en una situación tal que se ignora quien sea su propietario. La analogía con la situación propia de los vacantia es innegable, por lo que se puede avanzar la hipótesis de que primero para atribuirlos al aerarium y después al fisco se habría utilizado el régimen previsto en las leyes caducarias. La analogía encuentra ulterior confirmación en otro texto de Calistrato (D. 49, I4, 3, II). En opinión de Puliatti ${ }^{\mathrm{IO}}$, la analogía con la hipótesis caducaria se ve más clara en la figura de la autodelación, aunque la identidad entre ambas no es total, pues como ha señalado la doctrina ${ }^{\text {II }}$, mientras para el incapax la autodelación revestía carácter facultativo, para el inventor thesauri rige el principio de la obligación de la autodenuncia.

Otros autores ${ }^{\mathrm{12}}$, admitiendo la asimilación del tesoro a los bona vacantia, consideran que no es posible que esas leyes contuvieran ninguna prescripción relativa a los tesoros, y atribuyen el origen del régimen fiscal sobre los mismos, consiguiente a su configuración como bona vacantia, a Claudio.

Para Lauria ${ }^{\mathrm{I3}}$, quizá las leges Iuliae matrimoniales lo incluían entre los bona vacantia, o quizá el emperador Claudio lo consideró por primera vez. Más excéptica se muestra

\footnotetext{
${ }^{8}$ BONFANTE, «La vera data di un testo di Calpurnio Siculo e il concetto romano del tesoro», Mélanges F. Girard, I, París, I9I2, págs., I26 y ss., cita un texto de las Variae de Casiodoro, donde parece establecer una proximidad entre ambos conceptos: Var. 6, 8, 5: Caduca bona non sinis esse vacantia. Ita quod usurpator potuit invadere, tu fiscum nostrum facis iustis compendiis optinere. Proximos defunctorum nobis legaliter anteponis, quia in hoc casu principis persona post omnes est, sed hinc optamus nos acquirere, dummodo sint qui relicta debeant possidere.

${ }^{9}$ PROVERA, La vindicatio caducorum. Contributo allo studio del proceso fiscale romano, Torino, I964, págs. I40 y ss. En el mismo sentido, VOCI, Istituzioni di Diritto Romano, Milano, I996, pág. 273; GUZMAN, Derecho Privado Romano, I, Chile, I997, pág. 54I; IGLESIAS, Derecho Romano, Barcelona, I999, pág. I68); PANERO, Derecho Romano, Valencia, 2000, pág. 382); VENTURA, Derecho Romano. Curso de Derecho Privado, México, 2000, pág. 210.

${ }^{10}$ PULIATTI, Il de iure fisci di Callistrato e il processo fiscale in età severiana, Milano, I992, pág. I80.

" PROVERA, La vindicatio caducorum. Contributo allo studio del proceso fiscale romano, cit. pág. I42; SPAGNUOLO VIGORITA, Exsecranda pernicies. Delatori e fisco nell'età di Costantino, Napoli, I984, pág. I75.

${ }^{12}$ KÜBLER, «S.v. Thesaurus», Pauly-Wissowa, Realenzyklopädie der klassischen Altertumswissenschaft, VI, A I, Stuttgart, I936, pág. Io; HUBAUX-HICHTER, «Le fouiller et le trésor», Revue internationale des droits de l'Antoquité, 2, I949, págs. 426 y ss.; VOLTERRA, Instituciones de Derecho Privado Romano, trad. esp. de Daza, Madrid, I986, pág. 333; BUSACCA, «s.v. Tesoro», Enciclopedia del Diritto, XLIV, Milano, I992, pág. 384 nt. 32.

${ }^{13}$ LAURIA, «Dal possessore del tesoro all' 'inventor' (D. 4I.2.3.3.)», cit., pág. 27.
} 
Domínguez ${ }^{\mathrm{T}}$, cuando afirma que la asimilación de los tesoros a los bona vacantia se apoya más en motivos de pura lógica que en argumentos textuales, pues sólo en un fragmento de las Variae de Casiodoro parece establecerse un avecinamiento entre ambos conceptos. Tampoco se puede considerar demostrada la tesis que atribuye el régimen fiscal a Claudio.

Veamos las fuentes literarias en las que la doctrina se apoya para afirmar las pretensiones fiscales sobre los tesoros en época de la dinastía Julia-Claudia.

La primera es una égloga de Calpurnio Sículo, datada en tiempos del principado de Nerón que atribuye el tesoro hallado al descubridor.

Ecl. 4, II7 - I2I:

Iam neque damnatos metuit iactere ligones

Fossor et invento, si fors dedit, utitur auro,

Nec timet, ut nuper, dum iugera versat arator,

Ne sonet offenso contraria vomere massa.

Iamque palam presso magis et magis instat aratro.

El poeta viene a decir que no se debe tener miedo, a diferencia del período anterior, de hurtar con el arado un tesoro y se puede gozar plenamente del oro encontrado.

En opinión de Domínguez ${ }^{15}$, el texto se refiere a las investigaciones a que era sometido aquél que protagonizaba un hallazgo por parte de los funcionarios fiscales (las cuales presuponen lógicamente el reconocimiento de derechos del fisco sobre los tesoros), a fin de que declarase la verdadera entidad y cuantía del descubrimiento, tan molestas y gravosas que habrían provocado en las gentes un auténtico temor ante la idea del descubrimiento.

Hasta Bonfante $^{\mathrm{I} 6}$, la doctrina, haciéndose eco de la teoría avanzada por Godofredo y la opinión de antiguos filólogos, venía situando cronológicamente la cuarta égloga de Calpurnio Sículo bajo el principado de Caro y Carino (282-284 d.C.), dándose lugar a una errónea reconstrucción del régimen fiscal de la adquisición de los tesoros. Sobre la propuesta avanzada por Haupt ${ }^{17}$, Bonfante demuestra que la égloga va referida al principado de Nerón, atribuyendo la falsa cronología a la confusión con otra égloga de M. Aurelio Olimpo Nemesiano, ciertamente de la época de aquellos Emperadores.

Bonfante $^{\mathrm{r} 8}$ ha datado la égloga en los primeros años del reinado de Nerón. Domínguez $^{19}$ lo justifica afirmando que ya sea por el saneamiento de las finanzas imperiales (tal como habían sido heredadas de Claudio), ya sea por el deseo del emperador

${ }^{14}$ DOMÍNGUEZ, «Las pretensiones fiscales sobre los tesoros: Derecho romano y Código civil», El Derecho de familia y los derechos reales en la romanística española (1940-2000), Huelva, 2000, págs. 37I y ss.

${ }^{15}$ DOMÍNGUEZ, Las pretensiones fiscales sobre los tesoros: Derecho romano $y$ Código civil, cit., pág. 372 nt. 8 ; BUSACCA, s.v. Tesoro, cit., pág. $385 \mathrm{nt}$. 34, afirma que era frecuente el recurso de la tortura para que el descubridor testificase el verdadero valor del hallazgo. ss.

${ }^{16}$ BONFANTE, «La vera data di un testo di Calpurnio Siculo e il concetto romano del tesoro», cit., págs. I23 y

${ }^{17}$ HAUPT, De carminibus bucolicis Calpurnii et Nemesiani, Berlín, I854, pág. 358.

${ }^{\mathrm{I} 8}$ BONFANTE, «La vera data di un testo di Calpurnio Siculo e il concetto romano del tesoro», cit., pág. I24.

${ }^{19}$ DOMÍNGUEZ, «Las pretensiones fiscales sobre los tesoros: Derecho romano y Código civil», cit., pág. 37I nt. 7 . 
de granjearse el favor de su pueblo, tal como atestigua un pasaje de los Anales de Tácito (I3, 50), habrían favorecido ciertamente estos actos de liberalidad.

Por el contrario, Hubaux-Hicter ${ }^{2 \circ}$, aceptando esencialmente la interpretación de Bonfante, han propuesto como fecha de la égloga el final del reinado de Nerón, es decir, el año 65, mientras que la fecha de la reforma fiscal la sitúan entre los años 58 y 62, esto es, en la segunda parte de su reinado. Esgrimen distintos argumentos, especialmente, otro pasaje de la cuarta égloga ${ }^{2 \mathrm{I}}$ que muestra que las manifestaciones de adoración universal a Nerón no pueden situarse en los primeros años del reinado, sino en la segunda parte de la era neroniana; y el hecho de que la renuncia al derecho del fisco sobre los tesoros descubiertos contrastaría con el fuerte sometimiento a la influencia maternal del Emperador durante los primeros momentos de su reinado, pues Agripina que fallece en el año 59, nunca habría consentido tal medida dispositiva de su hijo. En esta línea, Busacca ${ }^{22}$ considera que si la égloga de Perseo fue compuesta entre los años 60 y 62, y si el autor del Satiricón muere en el año 66, la innovación neroniana debe situarse entre los años 58 y 62 .

La égloga de Calpurnio Sículo es interpretada por la doctrina como una renuncia por parte de Nerón a las pretensiones fiscales, afirmadas hasta poco tiempo atrás. Sin embargo, no hay acuerdo doctrinal sobre la participación del descubridor-delator en el tesoro hallado como premio por la actividad desarrollada en defensa de los derechos del aerarium en tiempos anteriores. Para Provera ${ }^{23}$, probablemente le correspondería la mitad de los bienes denunciados, es decir, el mismo premio que cuando se trataba de bienes caduca o vacantia; para Scarcella ${ }^{24}$, quizá fue atribuido al descubridor la totalidad del tesoro; para Domínguez ${ }^{25}$, desde el punto de vista de los derechos del fisco, considera que es poco probable, desde luego, que el derecho del fisco hubiese abarcado la totalidad del hallazgo; antes bien, se habría circunscrito sólo a una cuota o porción del mismo y ello así, más que nada, a efectos de invitar a las gentes a que denunciasen los hallazgos y para evitar, en cierta medida, que se defraudaran las expectativas del fisco.

La atribución del tesoro al descubridor bajo el principado de Nerón, resulta de numerosas referencias recogidas en las obras de Perseo, que imita a Horacio, y de Petronio.

Pers. Sat. 2, IO - I2:

...oh si

sub rastro crepet argenti mihi seria dextro

Hercule!

${ }^{20}$ HUBAUX-HICTER, «Le fouiller et le trésor», cit. 427 y ss. En el mismo sentido, LAURIA, « Dal possessore del tesoro all' 'inventor' (D. 4I.2.3.3.)», cit., pág. 28.

${ }^{21}$ Ecl. 4, I07: Scilicet omnis eum tellus, gens omnis adorat

diligiturque deis: quem sic taciturna verentur

arbuta, cuius iners audito nomine tellus

incaluit floremque dedit, cui silva vocato

densat odore comas, stupefacta regerminat arbos.

${ }^{22}$ BUSACCA, «Qualche osservazione sulle innovazioni introdotte dai divi fratres nel regime giuridico del tesoro», Scritti in onore di A. Falzea, IV, I99I, pág. I4I nt. 25); idem, «s.v. Tesoro», cit., pág. 384 nt. 33.

${ }^{23}$ PROVERA, La vindicatio caducorum. Contributo allo studio del proceso fiscale romano, cit., pág. I4I nt. 48.

${ }^{24}$ SCARCELLA, «Una nuova concezione del tesoro alla luce di C. I. IO.I5.I», cit., pág. 2 I3.

${ }^{25}$ DOMÍNGUEZ, «Las pretensiones fiscales sobre los tesoros: Derecho romano y Código civil», cit., pág. 374 nt. I3. 
Petron. Satyr. 88, 8:

Ac ne bonam quidem mentem aut bonam

Valitudinem petunt, sed statim antequam limen Capitolii tangant,

Alius domum promittit, si propinquum divitem extulerit,

Alius, si thesaurum effoderit, alius, si ad trecenties sestertium

Salvus perveniret.

La doctrina suele citar también el testimonio de Tácito y Suetonio, referido a la búsqueda por parte de Nerón del legendario tesoro que la reina Dido había llevado consigo al huir de Tiro y que, según le informó un caballero romano, se hallaba en África escondido en inmensas cavernas.

Tac., Ann. I6, I: Inlusit dehinc Neroni fortuna per vanitatem ipsius et promissa Caeselli Bassi, qui, origine Poenus, mente turbida, nocturnae quietis imaginem ad spem haud dubiae rei traxit, vectusque Romam, principis aditum emercatus, expromit repertum in agro suo specum altitudine inmensa, quo magna vis auri contineretur, non in formam pecuniae, sed rudi et antiquo pondere: lateres quippe praegraves iacere, adstantibus parte alia columnis, quae per tantum aevi occulta augendis praesentibus bonis. Ceterum, ut coniectura demonstrabat, Dido Phoenissam, Tyro profugam, condita Carthagine, illas opes abdidisse, ne novus populus nimia pecunia lasciviret, aut reges Numidarum, et alias infensi, cupidine auri ad bellum accenderentur . 2. Igitur Nero, non auctoris, non ipsius negotii fide satis spectata nec missis [visoribus ] per quos nosceret an vera adferrentur, auget ultro rumorem mittitque qui velut paratam praedam adveherent. Dantur triremes et delectum remigium iuvandae festinationi. Nec aliud per illos dies populus credulitate, prudentes diveersa fama tulere. Ac forte quinquennale ludicum secundo lustro celebrabatur: a vafibus oratoribusque praecipua materia in laudem principis adsumpta est: non enim solitas tantum fruges nec confusum <in > letallis aurum gigni, sed nova ubertate provenire terram, et obvias opes deferre deos, quaeque alia summa facundia nec minore adulatione servilia fingebant, securi de facilitate credentis. 3. Gliscebat interim luxuria spe inani, consumebanturque veteres opes, quasi oblatis quas multos per annos prodigeret. Quin et inde iam largiebatur, et divitiarum exspectatio inter causas paupertatis publicae erat. Nam Bassus, effosso agro suo latisque circum auris, dum hunc vel illum locum promissi specus adseverat, sequunturque non modo milites, sed populus agrestium, efficiendo operi adsumptus, tandem, posita vaecordia, non falsa antea somnia sua seque tunc primum elusum admirans, pudorem et metum morte voluntaria effigit. Quidam vinctum ac mox dimissum tradidere, ademptis bonis in locum regiae gazae.

Suet., Nero 31: Non in alia re tamen damnosior quam in aedificando domum a Palatio Esquilias usque fecit, quam primo transitoriam, mox incendio absumpteam restitutamque auream nominavit. De cuius spatio atque cultu suffecerit haec rettulisse. Vestibulum eius fuit, in quo colussus CXX pedum staret ipsius effigie; tanta laxitas, ut porticus triplices miliarias haberet; item stagnum maris instar, circunmsaeptum aedificiis ad urbium speciem; rura insuper arvis atque vinetis et pascuis silvisque varia, cum multitudine omnis generis pecudum ac ferarum. In ceteris partibus cuncta auro lita, distincta gemmis unionumque conchis erant; cenationes laqueatae tabulis eburneis versatilibus, ut flores, fistulatis, ut unguenta desuper spargerentur; praecipua centationum rotunda, quae perpetuo diebus ac noctibus vice mundi circumageretur; balineae marinis et albulis fluentes acquis. Eius modi domum cum absolutam dedicaret, hactenus comprobavit, ut se diceret quasi hominem tandem habitare coepisse. Praeterea incohabat piscinam a Miseno ad Avernum lacum contectam porticibusque conclusam, quo quidquid totis Bais 
calidarum aquarum esset converteretur; fossam ab Averno Ostiam usque, ut navibus nec tamen mari iretur, longitudinis per centum sexaginta milia, latitudinis, qua contrariae quinqueremes commearent. Quorum operum perficiendorum gratia quod ubique esset custodiae in Italiam deportari, etiam scelere convictos non nisi ad opus damnari praeceperat. Ad hunc inpemdiorum furorem, super fiduciam imperii, etiam spe quadam reprentina immensarum et reconditarum opum impulsus est ex indicio equitis $R$. Pro comperto pollicentis thesauros antiquissimae gazae, quos Dido regina fugiens Tyro secum extulisset, esse in Africa vastissimis specubus abditos ac posse erui parvula molientium opera.

Acertadamente la doctrina ${ }^{26}$ ha negado que de ambos testimonios se pueda extraer la conclusión de un cambio de las pretensiones fiscales por parte de Nerón. Rotondi ${ }^{27}$ considera que tienen un valor muy dudoso, parece que Ceselio Baso ignora la legislación fiscal que el propio Nerón había derogado entre los años 58 y 62 . Bonfante ${ }^{28}$, que ha negado a ambos textos todo valor jurídico, afirma que las pretensiones del fisco podían basarse en la cualidad del locus, sin embargo, en tal caso, debe tenerse en cuenta que África era provincia senatorial, no imperial, por lo que ninguna expectativa como dominus loci habría podido albergar el fisco respecto del hallazgo. Igualmente, Busacca ${ }^{29}$ opina que de estos episodios nada se puede extraer para demostrar que en los últimos años del principado de Nerón estuviese vigente un nuevo régimen que atribuía parte del tesoro al fisco.

Discutido resulta también un texto de Filóstrato, Vita Soph. 2, I, 3, en el que Ático, padre de Herodes el sofista, encuentra un tesoro en su casa de Atenas, del que informa a Nerva quien, magnánimamente, decide que puede conservarlo como cosa propia.

Bonfante, Lauria y Busacca $^{30}$ consideran que tampoco tiene un valor decisivo. Argumentan que Atenas era una ciudad federada, y, además, desconocemos el régimen de adquisición de los tesoros vigente en el derecho ático. Rotondi ${ }^{31} q u e$ tampoco le confiere valor jurídico, le resulta enigmática la consulta realizada al Emperador por Ático, que parece suponer un cierto derecho sobre el tesoro.

Por el contrario, otros autores como Della Porta, Kübler, Hill, Mayer-Maly, Scarcella o Domínguez ${ }^{32}$, afirman decididamente que algún derecho tendría o podría tener el fisco sobre el hallazgo, pues de otro modo no se explica la denuncia realizada.

${ }^{26}$ Cfr. DOMÍNGUEZ, «Las pretensiones fiscales sobre los tesoros: Derecho romano y Código civil», cit., pág. 372 nt. 9, afirma que es posible también que en los últimos años de su reinado (Nerón), movido por su incontrolable afán derrochador, hubiese reafirmado su derecho sobre los tesoros; si bien matiza que el testimonio de Tácito y de Suetonio no resulta decisivo en el sentido expuesto.

${ }^{27}$ ROTONDI, «I ritrovamenti archeologici e il regime dell'acquisto del tesoro», cit., pág. 3I9. Igualmente, LAURIA, «Dal possessore del tesoro all' 'inventor' (D. 4I.2.3.3.)», cit., pág. 28.

${ }^{28}$ BONFANTE, «La vera data di un testo di Calpurnio Siculo e il concetto romano del tesoro», cit., pág. I25 nt. 2 .

${ }^{29}$ BUSACCA, «S.v. Tesoro», cit., pág. 385 nt. 36.

${ }^{30}$ BONFANTE, «La vera data di un testo di Calpurnio Siculo e il concetto romano del tesoro», cit., pág. I34; LAURIA, «Dal possessore del tesoro all' 'inventor' (D. 4I.2.3.3.)», cit., pág. 28 nt. 23; BUSACCA, «S.v. Tesoro», cit., pág. 385 nt. 36 .

${ }^{31}$ ROTONDI, «I ritrovamenti archeologici e il regime dell'acquisto del tesoro», cit., 3I9.

${ }^{32}$ DELLA PORTA, L'istituto giuridico dell'acquisto del tesoro. Dissertazione di Laurea, Torino, I907, pág. 8; KÜBLER, «S.v. Thesaurus», cit., pág. IO; HILL, Tresaure Trove in Law and Pratice from the earliest Time to the present Day, Oxford, I936, pág. 26; MAYER-MALY, «Der Schatzfund in Justinians Institutionen», Studies in Justinian's Institutes in Memory of J.A.C. Thomas, a cura di P.G. Stein-A.D.E. Lewis, London, I983, pág. II3; 
A modo de conclusión, podemos afirmar que en época de la dinastía Julia-Claudia, adquiere relevancia la figura del descubridor, cuya aparición vincula la doctrina mayoritaria con las pretensiones fiscales, cuyo régimen vendría asimilado al de los bona vacantia, regulados en las leges Iulia et Papia. En los tiempos de Nerón, las fuentes unánimemente atribuyen el tesoro al descubridor, lo cual, con base en la égloga de Calpurnio Siculo, es interpretado como una renuncia por parte del fisco a sus pretensiones. Queda la duda de si las pretensiones fiscales fueron restablecidas por Nerva, seguramente no. Igualmente, nada seguro se puede afirmar sobre la participación del delator-descubridor como premio con anterioridad a la égloga de Calpurnio Siculo.

\section{La regulación de Adriano}

Constituye una opinión unánime en la doctrina romanística que sólo a partir de Adriano, cuya intervención en la materia conocemos con exactitud, poseemos información precisa y detallada sobre el régimen jurídico de la adquisición del tesoro.

La regulación adrianea, datada entre los años $\mathrm{II} 7$ y $138^{33}$, la conocemos a través de dos fuentes, una literaria, un fragmento de la vita Hadriani de Esparciano, y otra jurídica, un texto de las Instituciones de Justiniano.

SHA., vita Hadr. I8, 6: De thesauris ita cavit, ut, si quis in suo repperisset, ipse potiretur, si quis in alieno, dimidium domino daret, si quis in publico, cum fisco aequabiliter partiretur.

IJ. 2, I, 39: Thesauros, quos quis in suo loco invenerit, divus Hadrianus naturalem aequitatem secutus ei concessit, qui invenerit. Idemque statuit, si quis in sacro aut in religioso loco fortuito casu invenerit. At si quis in alieno loco non data ad hoc opera, sed fortuitu invenerit, dimidium domino soli concessit. Et convenienter, si quis in Caesaris loco invenerit, dimidium inventoris, dimidium Caesaris esse statuit. Cui conveniens est, et si quis in publico loco vel fiscali invenerit, dimidium ipsius esse, dimidium fisci vel civitatis.

En opinión de Mayer-Maly ${ }^{34}$, las Instituciones de Justiniano se inspiran, sobre todo, en la literatura elemental de la época clásica y, quizás también, de la época postclásica temprana; muchas veces no se presentan más que como una tercera versión junto a las Instituciones gayanas y las res cottidianae. A menudo completan textos que se basan en la literatura elemental por medio de exposiciones limitadas de la nueva legislación. Sin embargo, a veces constituyen la única o más importante fuente de conocimiento del derecho clásico o preclásico. Uno de los ejemplos más conocidos es el del tesoro, o lo que es lo mismo, la regulación dada por Adriano.

A pesar de la claridad con la que Adriano nos presenta la nueva regulación jurídica de la adquisición del tesoro, ello tan sólo es aparente, pues son muchos los interrogantes que sobre la misma existen.

La primera duda es la relativa a las fuentes utilizadas por los compiladores.

SCARCELLA, «Una nuova concezione del tesoro alla luce di C. I. Io.I5.I», cit., pág. 215 nt. 83; DOMÍNGUEZ, «Las pretensiones fiscales sobre los tesoros: Derecho romano y Código civil», cit., pág. 373 nt. IO.

${ }_{33}$ PULIATTI, Il de iure fisci di Callistrato e il processo fiscale in età severiana, cit., pág. I62; MARRONE, Lineamenti di Diritto Privato Romano, Torino, 200I, pág. I69.

${ }^{34}$ MAYER-MALY, «Der Schatzfund in Justinians Institutionen», cit., pág. Io9. 
Ferrini $^{35}$, sobre la base de algunos elementos formales, considera posible una derivación de las res cottidianae. La expresión «naturalem aequitatem secutus» es utilizada una vez en el libro XVI ad edictum provinciale, cuando Gayo escribe "proconsul naturali aequitate motus» (D. 38, 8, 2), y «et convenienter» aparece en Gai I, 8I; 2, 87; 3, 37; 4, I66; etc. «Fortuitu» probablemente pertenece al rescripto, ya que no se encuentra en Gayo.

Por el contrario, Zocco-Rosa ${ }^{36}$ afirma que desconocemos la fuente, por lo que dichas expresiones no prueban nada. No puede aducirse como prueba decisiva, que por una sola vez, Gayo haya escrito «naturali aequitate motus». De las otras citas no hay ninguna palabra que demuestre el origen gayano del pasaje. Además, la voz «fortuitu» sería una buena razón para descartar el origen gayano. Pero si no se puede afirmar que fortuitu tenga un origen compilatorio, ¿cómo se puede atribuir al texto un cierto origen gayano? A este origen se puede aludir únicamente como una sospecha; ¿pero puede una simple sospecha elevarse a la categoría de fuente cierta y definitiva? No.

En la misma línea, Mayer-Maly ${ }^{37}$ también rechaza la tesis de Ferrini. Afirma que no convencen sus argumentos formales, la «naturalis aequitas» aparece como causa de la regulación no solo en Gayo (D. 38, 8, 2), sino en muchos otros textos que hacen referencia a Adriano, pero en lo relativo a nuestro tema, la «naturalis aequitas» aparece en una importante constitución de época postclásica (C. Th. IO, I8, 2). Tampoco conduce a ningún argumento concluyente los criterios etimológicos (concessit, convenienter, cui conveniens), a los que hace referencia Ferrini.

Otra cuestión que ha preocupado a la doctrina es la naturaleza del procedimiento adoptado por Adriano.

Algunos autores como Mackenzie, Longo, Busacca o De las Heras ${ }^{38}$, debido al estado de las fuentes, hablan genéricamente de constitución.

Otros como Ferrini, Mayer-Maly o Puliatti ${ }^{39}$ consideran que se trata de un rescripto.

Rotondi, al que se une Ferrini modificando su criterio anterior ${ }^{40}$, se inclinan por un senadoconsulto propuesto por el Emperador, es decir, una oratio al Senado.

Bonfante $^{4 \mathrm{r}}$ considera que si Adriano ha ordenado ex novo la regulación del tesoro, la forma más adecuada habría sido la de un edicto o la de un mandato. No obstante, esta forma, en la época del Principado, es utilizada por los emperadores para el gobierno

${ }^{35}$ FERRINI, «Sulle fonti delle Istituzioni di Giustiniano», Bulletino dell'Istituto di diritto romano, I3, I9oI, pág. I49.

${ }^{36}$ ZOCCO-ROSA, Imp. Iustiniani Institutionum Palingenesia, I, Catania, I908, págs. 254 y s.

${ }^{37}$ MAYER-MALY, «Der Schatzfund in Justinians Institutionen», cit., págs. Io9 y ss.

${ }^{38}$ MACKENZIE, Estudios de Derecho Romano, traducción española de Innerárity-De Azcarate, Madrid, I876, pág. I95; LONGO, Corso di diritto romano. I diritti reali, Padova, I962, pág. IIo; BUSACCA, «S.v. Tesoro», cit., pág. 385 nt. 37; DE LAS HERAS, «Adquisición del tesoro en el Fuero de Cuenca: bases romanas y evolución posterior», cit., pág. 6I nt. 56.

${ }^{39}$ FERRINI, Sulle fonti delle Istituzioni di Giustiniano, cit., pág. I49; MAYER-MALY, «Der Schatzfund in Justinians Institutionen», cit., pág. IIo nt. 8; PULIATTI, Il de iure fisci di Callistrato e il processo fiscale in età severiana, cit., pág. I62.

${ }^{40}$ ROTONDI, «I ritrovamenti archeologici e il regime dell'acquisto del tesoro», cit., pág. 320; FERRINI, Manuale di Pandette, Milano, I900, pág. 359 y s. nt. 2.

${ }^{41}$ BONFANTE, «La vera data di un testo di Calpurnio Siculo e il concetto romano del tesoro», cit., pág. I29. 
provincial, en general se puede convenir que para las modificaciones del ius civile han utilizado los senadosconsultos. Admitido ello, se podría suponer, como hace Ferrini, que la forma utilizada por Adriano habría sido un senadoconsulto basado en la propuesta de Adriano, esto es, una oratio al Senado. Añade que también se podría suponer que la disposición adrianea no regulase los tesoros descubiertos in italico solo, sino los tesoros descubiertos en las provincias imperiales, y, si se quiere, en las provincias senatoriales, hipótesis que rechaza por falta de apoyatura textual. Por último, señala que cabe otra explicación más segura, que la disposición de Adriano represente una renuncia a los derechos del fisco: disponiendo de un derecho suyo, el Emperador podía razonablemente proceder a una regulación y a una distribución del tesoro en suelo itálico y mediante constitución.

Scarcella $\mathrm{a}^{42}$ considera que reconociéndole carácter casuístico y dado el contenido innovador, podría tratarse de un decretum. Siguiendo a Palazzolo, afirma que en gran parte de los decretos imperiales se trata de consideraciones de equidad que inducen al príncipe a abandonar la rigurosa interpretación del ius civile a favor de otra más benigna. La solución propuesta podría considerarse avalada por el hecho de que el nuevo régimen ha sido introducido por Adriano «naturalem aequitatem secutus».

Formalmente Mitteis ${ }^{43}$ ha considerado un tribonianismo la última frase del texto de las Instituciones «Cui conveniens est...dimidium fisci vel civitatis». Orestano ${ }^{44}$, por su parte, ha puesto en duda la genuidad de la referencia a las «civitates». Quizá, como afirma Masi ${ }^{45}$, es cierto que no se puede atribuir a Adriano el principio enunciado en la última frase de las Instituciones, pero debe reconocerse que el mismo respeta el criterio que inspira la regulación expuesta en la parte precedente y, además, dicho principio viene confirmado por el testimonio de Esparciano.

De la comparación de ambas fuentes se pueden apreciar las siguientes semejanzas y diferencias:

a) ambas fuentes utilizan la expresión «quis in suo», que podría proceder de la regulación adrianea;

b) la llamada a la «aequitas naturalis» sólo se recoge en las Instituciones;

c) la diferencia entre hallazgo en fundo propio y hallazgo en fundo ajeno es común a ambas;

d) la Historia Augusta hace referencia además al suelo público «in publico»; las Instituciones, sin embargo, distinguen cinco clases de suelo: sacer, religiosus, Caesaris, publicus y fiscalis;

e) el locus sacer y el religiosus es equiparado al suelo privado a efectos de la adquisición del tesoro; mientras que el tesoro descubierto en locus Caesaris, fiscalis y publicus, se reparte por mitad entre el descubridor y el emperador, el fisco o la ciudad, respectivamente;

\footnotetext{
${ }^{42}$ SCARCELLA, «Una nuova concezione del tesoro alla luce di C. I. IO.I5.I», cit., pág. 216 nt. 84.

${ }^{43}$ MITTEIS, Römiches Privatrecht bis auf die Zeit Diokletians, I, München-Leipzig, I935, pág. 355 nt. I8.

${ }^{44}$ ORESTANO, Il problema delle persone giuridiche in diritto romano, I, Torino, I968, pág. 253 nt. I73.

${ }^{45}$ MASI, Ricerche sulla res privata del Princeps, Milano, I97I, 38.
} 
f) por último, otra diferencia importante es el requisito de la casualidad del descubrimiento exigido en las Instituciones.

Dicha comparación de ambos textos ha llevado a la doctrina a plantear dudas sobre la autenticidad del fragmento de las Instituciones.

Para Guarino ${ }^{46}$, Adriano probablemente estableció que si el tesoro hubiese sido encontrado fortuitamente en territorio (itálico o provincial) perteneciente al princeps «locus Caesaris», al inventor le correspondería la mitad y sólo la otra mitad sería reclamable por el fiscus Caesaris. El resto, según el citado autor, lo hizo la interpretatio prudentium, llegando progresivamente a conclusiones que serían acogidas por el derecho justinianeo.

En la misma línea, De las Heras ${ }^{47}$ afirma que si comparamos el citado fragmento de las Instituciones con el texto de Esparciano, en el que se expone igualmente la solución adrianea, parece que lo expresado en el fragmento institucional (desde et convenienter hasta el final) pudiera corresponder a una adaptación posterior de lo establecido por Adriano. De manera que se sustituía publico por Caesaris loco y fisco por Caesaris, lo que permitía, a su vez, hacer más adelante la distinción publico loco vel fiscali - fisci vel civitatis.

Mayer-Maly ${ }^{48}$, en un extenso trabajo sobre el tema, concluye que parte de lo que Justiniano atribuye a Adriano, corresponde a una adaptación posterior de lo establecido por el Emperador de la dinastía de los Antoninos. El citado autor, destaca los siguientes elementos que aparecen en las Instituciones pero no así en la Historia Augusta:

a) la diferencia según las clases de fundos donde se descubre el tesoro;

b) la diferencia entre tesoro hallado por casualidad y tesoro buscado intencionadamente;

c) la apelación a la aequitas naturalis.

Respecto de la primera diferencia, como hemos visto anteriormente, la Historia Augusta hace referencia, junto al fundo propio y ajeno, al suelo público «in publico». Las Instituciones distinguen cinco clases de suelo: locus sacer, locus religiosus, locus Caesaris, locus publicus y terreno fiscalis. Para el citado autor, esta diferencia atribuida a Adriano, constituye el punto de partida de la tradición posterior inaugurada por los divi fratres, según el testimonio de Calistrato (D. 49, I4, 3, Iо y II). Respecto de la segunda diferencia, la casualidad del descubrimiento, considera Mayer-Maly que es mencionada por primera vez por Trifonino (D. 4I, I, 63). Lo mismo cabe decir con relación a la llamada a la aequitas naturalis, sorprendente en opinión de Bonfante $^{49}$ la justificación para el modo de adquisición más legislado, que aparece por primera vez en tema de adquisición del tesoro en una constitución de Teodosio I, del año 380, C. Th. I0, I8, 2: «in hac tamen naturali aequitate animadvertimus quoddam temperamentum adhibendum...». De todo ello, concluye Mayer-Maly que los elementos que aparecen en las Instituciones y que no tienen ninguna

\footnotetext{
${ }^{46}$ GUARINO, Diritto Privato Romano, Napoli, I984, pág. 582.

${ }^{47}$ DE LAS HERAS, «Adquisición del tesoro en el Fuero de Cuenca: bases romanas y evolución posterior», cit., pág. 62.

${ }^{48}$ MAYER-MALY, Der Schatzfund in Justinians Institutionen, cit., págs. III y ss. Igualmente, LUCHETTI, La legislazione imperiale nelle istituzioni di Giustiniano, Milano, I996, I34 y ss.

${ }^{49}$ BONFANTE, «La vera data di un testo di Calpurnio Siculo e il concetto romano del tesoro», cit., pág. I3I.
} 
concordancia en la Historia Augusta, habrían surgido en el período comprendido entre Marco Aurelio y Lucio Vero y los emperadores León y Zenón.

Frente a esta opinión, Busacca ${ }^{5 \circ}$ ha defendido acertadamente la genuidad de la disposición adrianea recogida en las Instituciones justinianeas. Afirma que los elementos mencionados en las Instituciones y omitidos en el texto de la vita Hadriani más que derivar de añadidos sucesivos al régimen adrianeo, que podrían inducir a considerarlos innovaciones postclásicas, son precisiones de distintos aspectos de la disposición adrianea, omitidos por el autor de la vita Hadriani, un histórico no jurista del siglo IV, que transmite la noticia de un procedimiento de Adriano, no vigente en su tiempo, en sus líneas esenciales pero sin la precisión propia de un texto jurídico.

De ambos textos, en opinión de Busacca $^{5 \mathrm{I}}$, resulta que Adriano atribuye íntegramente al descubridor el tesoro descubierto en un fundo de su propiedad; si el hallazgo tiene lugar en un fundo ajeno, el tesoro pertenece la mitad al descubridor y la otra mitad al dueño del fundo (privado). Con relación a los tesoros descubiertos en fundos no privados, los dos textos afirman sustancialmente el mismo régimen, si bien formulado de manera distinta: en el texto de la vita Hadriani, el tesoro descubierto en lugares públicos es atribuido la mitad al descubridor y la mitad al fisco; en el texto de las Instituciones, viene referida directamente a la constitución adrianea la atribución de la mitad al descubridor y de la mitad al emperador del tesoro descubierto en los loca Caesaris, mientras que es referida al principio inspirador de la constitución (cui conveniens est) la atribución de la mitad al descubridor y de la mitad al fisco y a la civitas de los tesoros descubiertos respectivamente en los loca fiscalia y publica. Añade que la atribución al fisco de la mitad del tesoro descubierto en lugares públicos (latu sensu) puede aparecer como una generalización de la detallada disposición adrianea (referida en las Instituciones), sobre todo a la luz de la notable extensión del ámbito de competencias del fisco que tiene lugar en el siglo III.

Para Busacca, los elementos mencionados en las Instituciones y omitidos en el texto de la vita Hadriani son:

a) la aequitas naturales como fundamento del procedimiento;

b) la atribución al descubridor de los tesoros descubiertos en los loca sacra y religiosa;

c) la necesidad de la casualidad del descubrimiento en los loca sacra, religiosa y aliena.

Acertadamente algunos autores como Nörr, Busacca o De las $\mathrm{Heras}^{52}$, consideran adrianea la llamada a la aequitas naturalis, la cual aparece como fundamento en otras decisiones de este Emperador ${ }^{53}$.

5o BUSACCA, «Qualche osservazione sulle innovazioni introdotte dai divi fratres nel regime giuridico del tesoro», cit., págs. I42 y ss.

${ }^{51}$ BUSACCA, «Qualche osservazione sulle innovazioni introdotte dai divi fratres nel regime giuridico del tesoro», cit., págs. I42 y s.

${ }^{52}$ NÖRR, «Ethik von Jurisprudenz in Sachen Schatzfund», en Bulletino dell'Istituto di diritto romano, 75, I972, pág. I5 nt. 22; BUSACCA, «S.v. Tesoro», cit., pág. I44 y nt. 35; DE LAS HERAS, «Adquisición del tesoro en el Fuero de Cuenca: bases romanas y evolución posterior», cit., pág. 6I.

${ }^{53}$ Gai., 3, 73: Et quia hac constitutione videbatur effectum, ut ne numquam isti homines tamquam cives Romani morerentur, quamvis eo iure postea usi essent, quo vel ex lege Aelia Sentia vel ex senatus consulto cives Romani essent, 
Respecto de la equiparación de los lugares sagrados y religiosos con los fundos privados a efectos de la adquisición del tesoro en ellos hallado, considera Busacca ${ }^{54}$ que no puede ser entendido como un añadido postclásico o justinianeo, a la vista del nuevo significado asumido por las res sacrae y la desaparición de las res religiosae en esta época, y su omisión en el texto de la vita Hadriani podría ser debido a su escasa aplicación.

En opinión de Impallomeni ${ }^{55}$, en la concepción de la cancillería imperial el suelo sagrado y religioso era considerado nullius en sentido absoluto, por lo que suponiendo la inexistencia del titular y, por tanto, alguien con quien poder repartir, se puede explicar que el descubridor adquiriese la totalidad del tesoro descubierto. En otras palabras, la constitución de Adriano implícitamente excluye la existencia de eventuales sujetos de derecho a los que atribuir la propiedad de los bienes sagrados y religiosos, ya sean aquellos los propios dioses, el pueblo romano, corporaciones públicas o privadas, individuos.

Respecto del requisito de la casualidad, entendido en el sentido que le atribuye Lozano $^{56}$, de que la actividad mediante la cual se descubre el tesoro deberá tener un objetivo distinto del descubrimiento mismo, Busacca ${ }^{57}$ duda de la clasicidad de este requisito. Por el contrario, para otros autores con mejor criterio como Voci, Scarcella, Puliatti, Luchetti o De las $\mathrm{Heras}^{5^{8}}$, el texto de las Instituciones no deja lugar a dudas, la casualidad se afirma con las expresiones «non data ad hoc opera» y «fortuitu», añaden que posteriormente y de manera continuada dicho requisito caracterizará el concepto de tesoro ${ }^{59}$.

Conviene precisar que Adriano exige la casualidad cuando el descubrimiento tenga lugar en fundo ajeno, o bien sea religioso o sagrado, por lo que podríamos estar ante una prohibición de derecho público de buscar por cuenta propia tesoros en terreno ajeno. Debiéndose concluir, por tanto, que nada podía adquirir ex lege el descubridor no casual en

divus Hadrianus iniquitate rei motus auctor fuit senatus consulti faciundi, ut qui ignorante vel recusante patrono ab imperatore ius Quiritium consecuti essent, si eo iure postea usi essent, quo ex lege Alia Sentia vel ex senatus consulto, si Latini mansissent, civitatem Romanam consequerentur, proinde ipsi haberentur, ac si lege Aelia Sentia vel senatus consulto ad civitatem Romanam pervenissent.

D. 5, 3, 22 (Paulus, XX ad Edictum): ...Nam et in Oratione Divi Hadriani ita est: «Dispicite, Patres conscripti, numquid sit aequum, possessorem non facere lucrum et pretium, quod ex aliena re perceperit, reddere, quia potest existimari, in locum hereditariae rei venditae pretium eius successisse, et quodammodo ipsum hereditarium factum».

D. 4O, I2, 43 (Pomponius, III Senatusconsultorum): ... Hadrianus Imperator rescripsit; cuius rescripti verba haec sunt: «Sicut non est aequum, fiducia libertatis, quae ex fideicommissi causa praestanda est, intercipere hereditariam pecuniam, ita nec libertati praestandae moram quaeri oportet. Quam primum ergo arbitrum dare debeat, apud quem constaret, quid servari posset heredei, antequam ad servum manumittendum compelleretur».

D. 49, I4, 3, 6 (Callistratus, I de iure fisci): ...Divus etiam Hadrianus in haec verba rescripsit: «Valde inhumanus mos est iste, quo retinentur conductores vectigalium publicorum et agrorum, si tantidem locari non possint; nam et facilius invenientur conductores, si scierint fore, ut, si peracto lustro discedere voluerint, non teneantur».

${ }^{54}$ BUSACCA, «Qualche osservazione sulle innovazioni introdotte dai divi fratres nel regime giuridico del tesoro», cit., pág. I44

${ }^{55}$ IMPALLOMENI, «Sulla capacità degli esseri soprannaturali in diritto romano», Studi Volterra, III, Milano, I97I, págs.. 39 y ss.; 67 y ss.

${ }^{56}$ LOZANO, Historia e Instituciones de Derecho Romano, Zaragoza, I999, pág. 384.

${ }^{57}$ BUSACCA, «S.v. Tesoro», cit., págs. I44 y s.

${ }^{58}$ VOCI, Istituzioni di Diritto Romano, cit., pág. 273 nt. 4; SCARCELLA, «Una nuova concezione del tesoro alla luce di C. I. IO.I5.I», cit., págs. $2 \mathrm{I} 6$ y s.; PULIATTI, Il de iure fisci di Callistrato e il processo fiscale in età severiana, cit., pág. I73 nt. 6I; LUCHETTI, La legislazione imperiale nelle istituzioni di Giustiniano, cit., págs. I34 y ss.; DE LAS HERAS, «Adquisición del tesoro en el Fuero de Cuenca: bases romanas y evolución posterior», cit., págs. Giy s.

59 Vid., D. 4I, I, 63, 3 (Tryphoninus, VII Disputationum); C. Th. IO, I8, 2 (Imppp. Gratianus, Valentinianus et Theodosius A.A.A. ad populum, urbis constantinopolitanae); C. J. Io, I5, I, I-4 (Impp. Leo et Zeno A.A. Epinico Consulari). 
fundo ajeno. Adriano con dicha prohibición habría querido proteger la propiedad e impedir que terceros vengan indebidamente a hacer búsquedas y excavaciones con las que adquirir la mitad de los tesoros eventualmente descubiertos. En definitiva, Adriano ha pretendido desalentar a los buscadores de tesoros de la forma más radical posible: privando a su actividad de cualquier potencial premio.

La disposición adrianea ha sido valorada por la doctrina de manera desigual respecto de los derechos del fisco. Así Rotondi ${ }^{6 \circ}$, partiendo de la limitación del derecho fiscal a los tesoros descubiertos en fundos provinciales, interpreta la disposición adrianea en el sentido de una renuncia del fisco o del erario, según se trate de provincias imperiales o senatoriales, a la mitad del tesoro a favor del descubridor. Por el contrario, Bonfante ${ }^{6 \mathrm{r}}$ que, al mismo tiempo, justifica el carácter de la disposición adrianea en cuanto que se trataría razona- de un derecho propio del emperador sobre los tesoros encontrados, al cual podría renunciar perfectamente mediante una constitución. En opinión de Domínguez ${ }^{62}$, Adriano renuncia totalmente a las pretensiones fiscales sobre los tesoros hallados en propiedad ajena y parcialmente a su derecho sobre los encontrados en terreno propiedad del fisco, a favor del inventor.

En nuestra opinión, carece de base textual la afirmación de una renuncia total a las pretensiones del fisco sobre los tesoros hallados en propiedad ajena. Para la época republicana, como hemos visto, las escasas y discutidas fuentes literarias y el polémico texto de Paulo, no permiten extraer datos seguros sobre el tema que nos ocupa. Por otra parte, tampoco resulta fácil compartir la afirmación de una renuncia parcial de los derechos del fisco a favor del inventor. En ninguna de las fuentes examinadas se establece la cuota de participación del fisco, a diferencia de lo que hace la disposición adrianea que fija la participación del fisco sobre el tesoro descubierto en lugares de su propiedad, pero no que ello suponga una disminución o limitación de sus pretensiones. Por tanto, como afirma Puliatti ${ }^{63}$, es el régimen de libertad a favor del inventor durante el Principado y el paso durante el Dominado a un régimen de vinculación y control por parte del Estado. La fase liberal tiene lugar bajo el principado de Nerón, donde se atribuye el tesoro única, totalmente, y sin excepción al inventor. Sucesivamente la disposición de Adriano, modificando profundamente la regulación neroniana, instaura un régimen semi liberal en el que, por un lado, reconoce el incontestable derecho del inventor, pero por otro lado, lo especifica, lo limita equitativamente frente a los derechos de terceros (dominus loci) y lo somete a control con la introducción de las pretensiones del Estado.

Por lo que hace a los tesoros descubiertos en fundos privados, lleva razón D'Ors ${ }^{64}$ cuando afirma que Adriano quita al actual propietario del inmueble una mitad del tesoro hallado, en favor del hallador.

\footnotetext{
${ }^{60}$ ROTONDI, «I ritrovamenti archeologici e il regime dell'acquisto del tesoro», cit., págs. 320 y s.

${ }^{61}$ BONFANTE, «La vera data di un testo di Calpurnio Siculo e il concetto romano del tesoro», cit., pág. I32.

${ }^{62}$ DOMÍNGUEZ, «Las pretensiones fiscales sobre los tesoros: Derecho romano y Código civil», cit., pág. 374 y ss.

${ }^{63}$ PULIATTI, Il de iure fisci di Callistrato e il processo fiscale in età severiana, cit., págs. I7I y s.

${ }^{64}$ D'ORS, Derecho Privado Romano, Pamplona, I997, pág. 2II nt. 8. Cfr. DE LAS HERAS, «Adquisición del tesoro en el Fuero de Cuenca: bases romanas y evolución posterior», cit., pág. 6I, para quien no parece muy acertada la postura de D'Ors.
} 
El emperador Adriano, inspirado en la equidad natural, atribuye el tesoro íntegramente al descubridor, si ha sido descubierto en un fundo de su propiedad y también si lo ha sido en un lugar religioso o sagrado de manera fortuita. Si el hallazgo fortuito tiene lugar en un fundo privado ajeno, o bien en un fundo propiedad del César, fiscal o público, el tesoro pertenece la mitad al descubridor y la mitad al dueño del fundo, es decir, al particular, al emperador, al fisco o a la ciudad, respectivamente. Se genera una situación de copropiedad por la que el dominus loci y el inventor adquieren a la vez e inmediatamente; en caso de que el hallazgo no haya sido fortuito, la totalidad del tesoro descubierto se atribuye al titular del fundo.

\section{Continuidad de la regulación adrianea}

El régimen establecido por Adriano respecto de los tesoros descubiertos en lugares privados no viene puesto en duda por el famoso texto de Paulo, donde formula su célebre definición del tesoro:

D. 4I, I, 3I, I (Paulus, 3I ad edictum): Thensaurus est vetus quaedam depositio pecuniae, cuius non extat memoria, ut iam dominium non habeat: sic enim fit eius qui invenerit, quod non alterius sit. Alioquim si quis aliquid vel lucr causa vel metus vel custodiae condiderit sub terra, non est thensaurus: cuius etiam furtum fit.

Algunos autores como Lauria, Busacca y, quizá, Mayer-Maly ${ }^{65}$, afirman que los tesoros descubiertos en lugares privados son atribuidos en su totalidad al descubridor.

Más acertada nos parece la opinión de Scarcella ${ }^{66}$ cuando afirma que el texto de Paulo precisa los requisitos jurídicos que ha de tener el tesoro, y sólo cuando dichos requisitos concurren, nace sobre el mismo un derecho a la adquisición por parte del descubridor. Esto no significa que junto a la adquisición del descubridor no se dé también aquella del dominus loci. Por tanto, en el momento del descubrimiento coexisten sobre el tesoro dos diversas pretensiones, cada una de ellas con su propio fundamento: el objeto descubierto, calificado como tesoro, corresponderá la mitad al descubridor y la mitad al propietario del lugar.

En el mismo sentido se pronuncia De las $\mathrm{Heras}^{67}$, cuando escribe que el texto de Paulo no va destinado a determinar en qué casos o en qué porción se adquiere el tesoro, sino que simplemente intenta distinguir el supuesto en el que un descubridor puede incurrir en hurto y el supuesto en que un descubridor puede quedarse con el tesoro, esto es, con lo que le corresponda del tesoro, lo que otros autores consideran distinción entre tesoro impropio y tesoro propio. Además sería muy difícil la subsistencia del texto, sin alterar, si incurriera en contradicción con el régimen justinianeo, al igual que los demás textos del Digesto que se puedan citar.

${ }^{65}$ LAURIA, «Dal possessore del tesoro all' 'inventor' (D. 4I.2.3.3.)», cit., pág. 30; BUSACCA, «Qualche osservazione sulle innovazioni introdotte dai divi fratres nel regime giuridico del tesoro», cit., pág. I48; idem, «S.v. Tesoro», cit., pág. 386; MAYER-MALY, «Der Schatzfund in Justinians Institutionen», cit., pág. II2, afirma que «Das Corpus iuris besitzt nicht nur die bekannte thensaurus-Definition des Paulus (D.4I.I.3I.I), die übrigens nur am Eigentumserwerb des Finders orientiert ist (fit eius qui invenerit)». Modifica su anterior criterio en Thensaurus meus, cit., 284, cuando considera que el tesoro es descubierto en un fundo del invento.

${ }^{66}$ SCARCELLA, «Una nuova concezione del tesoro alla luce di C. I. IO.I5.I», cit., pág. 2 I7 nt. 86.

${ }^{67}$ DE LAS HERAS, «Adquisición del tesoro en el Fuero de Cuenca: bases romanas y evolución posterior», cit., pág. 63 . 
Igualmente mantiene vigente el régimen adrianeo una constitución de los divi fratres, Marco Aurelio y Lucio Vero, de la que nos informa Calistrato.

D. 49, I4, 3, II (Callistratus, III De iure Fisci): Deferre autem se nemo cogitur, quod thensaurum invenerit, nisi ex eo thensauro pars fisco debeatur.

Busacca $^{68}$ considera que dicha disposición corresponde fielmente a una parte de la constitución de los divi fratres dirigida a regular la adquisición del tesoro descubierto en fundos privados, donde se pone de relieve no la obligación de denunciar el hallazgo del tesoro sobre el que existen pretensiones fiscales (esto es, in loca publica, Caesaris, fiscalia, religiosa y monumenta), sino la exención de tal obligación si el tesoro es inmune a tales pretensiones, es decir, cuando el descubrimiento tenga lugar en un fundo privado.

El régimen adrianeo permanece vigente a principios del siglo III, según atestiguan varios textos de Trifoninoy uno de Ulpiano.

D. 4I, I, 63 pr. (Tryphoninus, VII Disputationum): Si is qui in aliena potestate est thensaurum invenerit, in persona eius cui adquirit hoc erit dicendum, ut, si in alieno agro invenerit partem ei adquirat, si vero in parentis dominive loco invenerit, illius totus sit, si autem in alieno, pars $^{69}$.

El texto, escrito durante la corregencia de Caracalla y $\mathrm{Geta}^{70}$, plantea el problema de la adquisición de la propiedad del tesoro descubierto por persona «in potestate». Trifonino distingue entre el tesoro descubierto en el fundo propiedad del titular de la potestas, y el descubierto en fundo ajeno. Siguiendo la regulación adrianea, considera para el primer supuesto que el tesoro pertenece al titular de la potestas; para el segundo supuesto, el descubridor «partem ei (domino) adquirat», lo que significa que la otra mitad ipso iure corresponde al propietario del fundo ${ }^{75}$.

D. 4I, I, 63, I (Tryphoninus, VII Disputationum): Si communis servus in alieno invenerit, utrum pro dominii partibus, an semper aequis acquiret? Et simile est, atque in hereditate, vel legato, vel quod ab aliis donatum servo traditur, quia et thesaurus donum fortunae creditur; scilicet ut pars, quae inventori cedit, ad socios, pro qua parte servi quisque dominus est, pertineat.

El jurista plantea el caso de un esclavo que se encuentra en copropiedad y que descubre un tesoro en un fundo ajeno. Se plantea la cuestión de si adquirirá para el copropietario en función de su cuota o lo repartirán a partes iguales. Trifonino resuelve la cuestión mediante una analogía entre el tesoro y la herencia o legado, afirmando que la

${ }^{68}$ BUSACCA, «Qualche osservazione sulle innovazioni introdotte dai divi fratres nel regime giuridico del tesoro», cit., págs. I52 y s.

${ }^{69}$ El texto ha sido considerado interpolado por SCHULZ, «Fr. 63 D. 4I, I (Zur Lehre vom Schatzerwerb)», Zeitschrift der Savigny-Stiftung für Rechtsgeschichte, 35, I9I4, págs. 94 y ss. Cfr. en contra BONFANTE, «La vera data di un testo di Calpurnio Siculo e il concetto romano del tesoro», cit., pág. I32 nt. I; BUSACCA, «Qualche osservazione sulle innovazioni introdotte dai divi fratres nel regime giuridico del tesoro», cit., pág. I43 nt. 29. 80 .

${ }^{70}$ Cfr. FITTING, Alter und Folge der Schiften römischen Juristen von Hadrian bis Alexander, Halle, I908, pág.

${ }^{7 \pi}$ Así, BONFANTE, «La vera data di un testo di Calpurnio Siculo e il concetto romano del tesoro», cit., pág. I47; SCIALOJA, Teoria della proprietà nel diritto romano, II, Roma, I933, pág. 57; SCARCELLA, «Una nuova concezione del tesoro alla luce di C. I. Io.I5.I», cit., pág. 2I7 nt. 86; BUSACCA, «S.v. Tesoro», cit., pág. 386; DE LAS HERAS, «Adquisición del tesoro en el Fuero de Cuenca: bases romanas y evolución posterior», cit., pág. 68; DOMÍNGUEZ, «Las pretensiones fiscales sobre los tesoros: Derecho romano y Código civil», cit., pág. 375. 
parte correspondiente al inventor se distribuirá entre los copropietarios en proporción a la cuota que cada uno tenga sobre el esclavo-descubridor. Respecto de la otra mitad, corresponderá al propietario del fundo donde se produce el hallazgo. Como vemos, Trifonino tiene muy presente para resolver el caso lo establecido por la disposición adrianea $^{72}$.

D. 4I, I, 63, 2 (Tryphoninus, VII Disputationum): Si communis servus in domini unius fundo proprio invenit, de parte, quae soli domino semper cedit, non est dubium, quin solius domini praedii sit; verum, an aliquid ex parte ferat alter socius, videndum est, et numquid simile sit, atque quum stipulatur servus iussu unius domini, aut per traditionem aliquid accipit vel nominatim alteri; quod magis dici poterit.

A diferencia del texto anterior, el jurista plantea el caso de un esclavo que se encuentra en copropiedad y que descubre un tesoro en un fundo propiedad de uno de los copropietarios. Se plantea la cuestión de si adquirirá únicamente el copropietario titular del fundo donde se ha producido el hallazgo, o también el otro copropietario del esclavo descubridor. Trifonino, aplicando la regulación adrianea, considera que se trata de un tesoro descubierto «in suo» por lo que el esclavo adquiere el tesoro íntegramente para el dominus loci.

D. 4I, I, 63, 3 (Tryphoninus, VII Disputationum): Quodsi servus, in quo ususfructus alienus est, invenerit in eius loco, qui servum proprium habet, an totum illius sit, et si in alieno, an partem eidem acquirat, an vero fructuario? Inspectio in illo est, num ex operis servi acquiratur. Finge, terram fodientem invenisse; ut hoc dicatur fructuarii esse, quod vero subito in abdito loco positum nihil agens, sed aliter ambulans invenit, proprietatis domini sit. Ego nec illius ad fructuarium pertinere partem arbitror; nemo enim servorum opera thesaurum quaerit, nec ea propter tunc terram fodiebat, sed alii rei operam insumebat, et fortuna aliud dedit. Itaque si in ipsius fructuarii agro invenerit, puto partem solam, ut agri dominum, habiturum alteram ad eum, cuius in servo proprietas est, pertinere.

Se plantean dos hipótesis para el caso del descubrimiento de un tesoro por parte de un esclavo que se encuentra en usufructo, la primera, que el descubrimiento se produzca en un fundo propiedad del nudo propietario; la segunda, que el fundo pertenezca al usufructuario. El problema es si la parte del descubridor corresponde al propietario del esclavo o al titular del derecho de usufructo.

Mayer-Maly ${ }^{73}$ considera que surge como criterio la discusión de si se adquiere ex operis servi. En virtud de ello cabe preguntarse ¿el esclavo que excava intencionadamente adquirirá para el usufructuario o para su propietario, frente a otro que encuentra algo aliter ambulans?. Trifonino opinaba que la mitad perteneciente al descubridor debería adjudicarse siempre al propietario del esclavo. El motivo era: nemo enim servorum opera thensaurum quaerit nec eapropter tunc terram fodiebat, sed alii rei operam insumebat et fortuna aliud dedit. Mayer-Maly interpreta que Trifonino, basándose en la regulación adrianea, no concede ninguna participación al descubridor, sólo se daría en el caso de tesoro descubierto por casualidad.

\footnotetext{
${ }^{72}$ Cfr. MAYER-MALY, «Ducente fortuna», en Studies in Roman Law in Memory of A.A. Schiller, a cura di R.S. Bagnall-W.V. Harris, Leiden, I986, págs. I4I y s.

${ }^{73}$ MAYER-MALY, «Der Schatzfund in Justinians Institutionen», cit., pág. II6; idem, «Ducente fortuna», cit., pág. I42.
} 
D. 24, 3, 7, I2 (Ulpianus, XXXI ad Sabinum): Si fundum viro uxor in dotem dederit isque inde arbores deciderit, si hae fructus intelleguntur, pro portione anni debent restitui puto autem, si arbores caduae fuerunt vel gremiales, dici oportet in fructu cedere), si minus, quasi deteriorem fundum fecerit, maritus tenebitur. Sed et si vi tempestatis ceciderunt, dici oportet pretium earum restituendum mulieri nec in fructum cedere, non magis, quam si thensaurus fuerit inventus: in fructum enim non computabitur, sed pars eius dimidia restituetur quasi in alieno inventi.

El texto redactado bajo Caracalla ${ }^{74}$, supone en opinión de Lauria ${ }^{75}$ una nueva decisión basada en la equidad, teniendo en cuenta el régimen del tesoro y el de la restitución de la dote. Ulpiano para atribuir la mitad del tesoro al marido que lo ha descubierto en el fundus dotalis, lo equipara al descubridor en fundo ajeno; por lo que se refiere a la mujer, adquiere la mitad del tesoro y el fundo. Igualmente, Scarcella y Busacca ${ }^{76}$ interpretan el texto en el sentido de que el marido, descubridor del tesoro en el fundus dotalis, en el momento de la disolución del matrimonio retiene para sí la mitad de lo que le corresponde, debiendo entregar la otra mitad a la mujer, que es adquirida en virtud de su propiedad del fundo, junto con el propio fundo.

\section{La regulación de Marco Aurelio y Lucio Vero}

Entre los años $\mathrm{I} 60$ y $\mathrm{I}^{\mathrm{I}} \mathrm{I}^{77}$, tiene lugar una extensión de las pretensiones fiscales introducida por los divi fratres, Marco Aurelio y Lucio $\mathrm{Vero}^{78}$, en el régimen jurídico de la adquisición del tesoro, que en opinión de Busacca $^{79}$ se debe no a una voracidad fiscal de los divi fratres, sino a la precaria situación de las finanzas imperiales, causadas por las guerras de Oriente y por la peste, que diezmó la población del Imperio en el año i65 y en los años siguientes.

Dicha constitución viene recordada por Calistrato, en el libro tercero de iure fisci, escrito bajo el principado de Septimio Severo, antes de la incorporación al poder de Caracalla en el $197^{80}$.

D. 49, I4, 3, IO (Callistratus, III De iure Fisci): Si in locis fiscalibus vel publicis religiosisve aut in monumentis thensauri reperti fuerint, divi fratres constituerunt, ut dimidia pars ex his fisco vindicaretur. Item si in Caesaris possessione repertus fuerit, dimidiam aeque partem fisco vindicari. II. Deferre autem se nemo cogitur, quod thensaurum invenerit, nisi ex eo II2.

${ }^{74}$ Cfr. FITTING, Alter und Folge der Schiften römischen Juristen von Hadrian bis Alexander, Halle, I9o8, pág.

${ }^{75}$ LAURIA, «Dal possessore del tesoro all' ‘inventor’ (D. 4I.2.3·3.)», cit., pág. 3I.

${ }^{76}$ SCARCELLA, «Una nuova concezione del tesoro alla luce di C. I. Io.I5.I», cit., pág. 2I7 nt. 86; BUSACCA, «S.v. Tesoro», cit., pág. 386.

${ }^{77}$ Cfr. PULIATTI, Il de iure fisci di Callistrato e il processo fiscale in età severiana, cit., pág. I62.

${ }^{78}$ BUSACCA, «Qualche osservazione sulle innovazioni introdotte dai divi fratres nel regime giuridico del tesoro», cit., pág. I35 nt. I; idem, «s.v. Tesoro», cit., pág. 385 nt. 4I, considera que esta disposición, al igual que otras atribuidas a los divi fratres, fue probablemente realizada por Marco Aurelio, al cual, a causa de las largas ausencias de Lucio Vero de Roma, incumbía la dirección de los asuntos internos.

${ }^{79}$ BUSACCA, «Qualche osservazione sulle innovazioni introdotte dai divi fratres nel regime giuridico del tesoro», cit., pág. I40.

${ }^{80}$ Cfr. FITTING, Alter und Folge der Schiften römischen Juristen von Hadrian bis Alexander, cit., págs. 69 y s. 
thensauro pars fisco debeatur. Qui autem, cum in loco fisci thensaurum invenerit, partem ad fiscum pertinentem suppresserit, totum cum altero tanto cogitur solvere.

Resulta difícil conocer por el estado actual del texto el contenido exacto de la constitución de los divi fratres $^{8 \mathrm{r}}$.

Desde una óptica general, Puliatti ${ }^{82}$ ha destacado: a) el desinterés de Calistrato, a nivel teórico, por los problemas dogmáticos del tesoro. En efecto, se distancia de la tradición jurisprudencial, a diferencia de cuanto hacen Paulo y Papiniano, Calistrato omite no sólo la noción y el concepto jurídico de tesoro y, por tanto, la definición de la figura y de sus elementos constitutivos, sino también los principios del ius possessionis ${ }^{8_{3}}$, la naturaleza de la adquisición y las complejas relaciones derivadas del hallazgo, en particular entre inventor y dominus loci; b) el desinterés, a nivel práctico, por la circunstancia (búsqueda programada e intencional o casualidad; autorizadas o abusivas) y por los modos de la inventio; c) coherente con la vigencia del derecho, Calistrato omite las referencias a la normativa más remota, que por lo que se refiere a la de Adriano ciertamente conocía, y se limita a la cita de la más próxima, esto es, la constitución de Marco Aurelio y Lucio Vero, evidentemente porque en el momento de la redacción del De iure fisci la misma constituía la normativa vigente sobre la inventio thesauri.

Volviendo al texto de Calistrato, Puliatti ${ }^{84}$ lo califica como aparentemente unitario. A pesar de contener en su conjunto una disciplina coherente, es el resultado de una mezcla de disposiciones, cuya diversidad y diferente origen se pone también de manifiesto en aspectos formales. La paternidad del par. Io: reparto del tesoro entre inventor y fiscus y ejercicio de la vindicatio, se puede atribuir a los divi fratres; no ocurre lo mismo con el par. II: no obligatoriedad de la denuncia cuando no existan derechos del fisco y sanción en caso contrario, que quizá proviene de otro procedimiento normativo, hecho suyo por alguno de los Severos, considerando el rigor de la política fiscal severiana frente a la evasión y a su

\footnotetext{
${ }^{81}$ La doctrina ha destacado, desde el punto de vista formal y sustancial, problemas relativos a la integridad, genuidad y estructura del texto. Fundándose en las relaciones entre aerarium y fiscus, MITTEIS, Römiches Privatrecht bis auf die Zeit Diokletians, I, cit., pág. 355 nt. I8, sostiene que los términos «fiscalibus vel» y «fiscus» deben corregirse, particularmente el segundo debe sustituirse por «aerarium». Por razones análogas, SCHERILLO, Lezioni di diritto romano. Le cose, Milano, I945, págs. IO2 y s., propone sustituir «fiscus» por «populus». BUSACCA, «Qualche osservazione sulle innovazioni introdotte dai divi fratres nel regime giuridico del tesoro», cit., pág. 136 nt. 4, califica ambas observaciones como inaceptables y se pronuncia sobre la genuidad del texto.

PULIATTI, Il de iure fisci di Callistrato e il processo fiscale in età severiana, cit., pág. I64 nt. 52, observa a la crítica de Mitteis que en época severiana la diferencia institucional entre aerarium y fiscus, especialmente por lo que se refiere a la clase de bienes objeto de la disposición de los divi fratres, estaba ya superada; añade, que se puede suponer que Calistrato había querido dar a su exposición un sentido histórico-evolutivo, mientras su construcción, siendo de naturaleza procesal y dirigida a la práctica, refleja la realidad jurídica contemporanea. Respecto de la posición de Scherillo, considera que en Calistrato existe la identificación conceptual y terminológica entre fiscus y populus.

Otros autores han expresado dudas sobre la autenticidad del texto, así HUVELIN, Études sur le furtum dans le très ancien droit romain, I: Les sources, Lyon-Paris, I9I5, págs. 275 y ss.; HILL, Tresaure Trove in Law and Pratice from the earliest Time to the present Day, cit., pág. 26 nt. 4, que considera interpolada la expresión «cum altero tanto»; SEGRÉ, «La denominazione di actio confessoria in particolare per la rivendicazione dell'usufrutto e delle servitù», Mélanges Girard. Étude de droit romain, II, Paris, I9I2, págs. 5 IIy ss., especialmente 537 nt. I7.

${ }^{82}$ PULIATTI, Il de iure fisci di Callistrato e il processo fiscale in età severiana, cit., págs. I64 y ss.

${ }^{83}$ Como es sabido, los textos básicos relativos al ius possessionis en tema de tesoro son aquellos de Trifonino (D. 4I, I, 63, 3, VII Disputationum), de Paulo (D. 4I, 2, 3, 3, LIV ad Edictum) y de Papiniano (D. 4I, 2, 44 pr., XXIII Quaestionum).

${ }^{84}$ PULIATTI, Il de iure fisci di Callistrato e il processo fiscale in età severiana, cit., págs. I74 y s.
} 
tendencia a valorar las espontáneas denuncias con el fin de incrementar las expectativas tributarias.

Por el contrario, acertadamente Busacca ${ }^{85}$ se inclina por la coherencia de todo el fragmento y atribuye su paternidad a los divi fratres, justificando las diferencias formales por la reelaboración de Calistrato de parte de las normas contenidas en las disposiciones originarias.

Como vemos, el jurista considera la inventio thesauri desde un ángulo muy concreto, el ius singulare del fiscus, desde el cual el régimen presentado por Calistrato sería el siguiente:

a) atribución al fisco del ejercicio de la vindicatio sobre la mitad de los tesoros descubiertos in locis fiscalibus vel publicis religiosisve aut in monumentis ${ }^{86}$;

\footnotetext{
${ }^{85}$ BUSACCA, «Qualche osservazione sulle innovazioni introdotte dai divi fratres nel regime giuridico del tesoro», cit., págs. I37 y s.

${ }^{86}$ Resulta muy discutido en la doctrina el concepto de «loca fiscalia».

SCHERILLO, Lezioni di diritto romano. Le cose, cit., págs. IO2 y s., los identifica o equipara con las possessionis Caesaris, como fundo del patrimonium principis, patrimonio de la corona, que con el transcurso del tiempo se irá distinguiendo del fisco.

CANNATA, «Possessio', 'possessor', 'possidere’» nelle fonti giuridiche del basso impero romano. Contributo allo studio del sistema dei rapporti reali nell'epoca postclassica, Milano, I962, pág. I53 nt. 24, los identifica con los bienes inmuebles pertenecientes a la ratio privata. En contra, MASI, Ricerche sulla res privata del Princeps, cit., pág. 40 nt. I89.

CERAMI, «Contrahere cum fisco», Annali del Seminario giuridico della R. Università di Palermo, 34, I973, pág. 357 nt. I26, los identifica con los loca publica. La concentración en la esfera fiscal de todo cuanto concernía a las finanzas públicas, había conducido a una cierta equiparación no sólo terminológica, sino también sustancial entre las res fiscales y las res publicae, como lo prueba el pasaje de Calistrato, al que atribuye a «vel» en el inciso «fiscalibus vel publicis» valor copulativo y no disyuntivo.

BUSACCA, «Qualche osservazione sulle innovazioni introdotte dai divi fratres nel regime giuridico del tesoro», cit., pág. I39 nt. I6, los identifica con cualquier lugar en el que se haya descubierto un tesoro grabado con pretensiones fiscales.

PULIATTI, Il de iure fisci di Callistrato e il processo fiscale in età severiana, cit., pág. I76 nt. 67, considera que serían las propiedades pertenecientes al fisco que pueden ser objeto de negocios jurídicos.

Los loca publica serían los fundos pertenecientes a las ciudades. Cfr. VOCI, Nuovi studi sulla legislazioni del Tardo Impero, Padova, I989, I2 nt. 44, que cita D. 49, I4, 3, Io (Callistratus, III de iure fisci) y I.J. 2, I, 39.

Los loca religiosa son los lugares con inhumación de cadáveres, D. 47, I2, 4 (Paulus, XXVII ad Edictum): Sepulchra hostium religiosa nobis non sunt; D. II, 7, 2 pr. (Ulpianus, XXV ad Edictum): Locum in quo servus sepultus est religiosum esse Aristo ait , 5: Celsus autem ait: non totus, qui sepulturae destinatus est, locus religiosus fit, sed quatenus corpus humatum est, 9: Is qui pignori dedit agrum et in eum suorum mortuum intulerit, religiosum eum facit; D. II, 7, 4 (Ulpianus, XXV ad Edictum): Scriptus heres prius quam hereditatem adeat patrem familias mortuum inferendo locum facit religiosum; D. II, 7, 34 (Paulus, LXIV ad Edictum): Si locus sub condicione legatus sit, interim heres inferendo mortuum non facit locum religiosum; D. II, 7, 36 (Pomponius, XXVI ad Quintum Mucium): Cum loca capta sunt ab hostibus, omnia desinunt religiosa vel sacra esse; D. II, 7, 43 (Papinianus, VIII Quaestionum): Sunt personae, quae, quamquam religiosum locum facere non possunt, interdicto tamen de mortuo inferendo utiliter agunt; D. II, 7, 44 (Paulus, III Quaestionum): Cum in diversis locis sepultum est, uterque quidem locus religiosus non fit. Sobre el tema, vid. PULIATTI, Il de iure fisci di Callistrato e il processo fiscale in età severiana, cit., pág. I76 nt. 67, con amplia bibliografía.

Los monumenta serían los lugares destinados al enterramiento, ocupados o no por cadáveres, formando en el primer caso verdaderas tumbas, y en el segundo, los cenotafios, D. II, 7, 2, 6 (Ulpianus, X ad Edictum): Monumentum est, quod memoriae servandae gratia existat; D. II, 7, 6 pr. - I (Ulpianus, XXV ad Edictum): Liberti autem nec sepeliri nec alios inferre poterunt, nisi heredes extiterint patrono, quamvis quidam inscripserint monumentum sibi libertisque suis fecisse: et ita Papinianus respondit et saepissime idem constitutum est. Si adhuc monumentum purum est, poterit quis hoc et vendere et donare. Si cenotaphium fit, posse hoc venire dicendum est: nec enim esse hoc religiosum divi fratres rescripserunt; D. II, 7, 42 (Florentinus, VII Institutionum): Monumentum generaliter res est memoriae causa in posterum prodita: in qua si corpus vel reliquae inferantur, fiet sepulchrum, si vero nihil eorum inferatur, erit monumentum memoriae causa factum, quad Graeci inane sepulcrum appellant; D. II, 8, 5 (Ulpianus, I Opinionum): Si in eo monumento, quod impeerfectum esse dicitur, reliquae hominis conditae sunt, nihil impedit quominus id perficiatur. Sed si religiosus locus iam factus sit, pontifices explorare debent, quatenus salva religione desiderio reficiendi operis medendum sit. Sobre el tema, vid. PULIATTI, Il de iure fisci di Callistrato e il processo fiscale in età severiana, cit., pág. 176 nt.67) con amplia bibliografía.
} 
b) ejercicio de la vindicatio sobre la mitad del tesoro descubierto in Caesaris possessione $^{87}$

c) exención para el descubridor de la obligación de denunciar el descubrimiento del tesoro, cuando sobre el mismo no exista ningún derecho del fisco;

d) obligación de entregar todo el tesoro descubierto en un locus fisci y pagar una pena pecuniaria cuando el descubridor haya ocultado el descubrimiento al fisco.

Busacca $^{88}$ observa que a pesar de que Calistrato refiere expresamente a la constitución de los divi fratres sólo la atribución al fisco del ejercicio de la vindicatio sobre la mitad de los tesoros descubiertos en los loca fiscalia, publica, religiosa y en los monumenta, parece muy probable que la misma constitución haya también previsto el ejercicio de la vindicatio sobre la mitad de los tesoros descubiertos en los praedia Caesaris, cuya distinta presentación por Calistrato puede deberse a las modificaciones introducidas en el patrimonio imperial entre Marco Aurelio y Lucio Vero y Septimio Severo.

Respecto de la exención para el descubridor de la obligación de denunciar cuando sobre el mismo no exista ningún derecho del fisco, considera Busacca que permite afirmar, en caso contrario, el ejercicio de la vindicatio con la introducción de la obligación para el descubridor de denunciar al fisco el tesoro descubierto sobre el que pueden existir pretensiones fiscales y, por tanto, estaría vinculada a la disposición anterior, y aparecería recogida en el mismo contexto normativo.

Por lo que se refiere a la obligación de denuncia al fisco del tesoro descubierto, que según el texto de Calpurnio Sículo parece haber sido una constante desde el mismo momento en que surgieron las pretensiones fiscales y la correspondiente sanción, consideramos que la expresión «totum cum altero tanto» debe interpretarse en el sentido de devolver la totalidad del hallazgo y pagar una cantidad igual a su valor a título de pena ${ }^{{ }^{9}}$, ya que como afirma Puliatti ${ }^{\circ}$ no parece una verdadera y propia sanción castigar al descubridor con la pérdida de su mitad sobre el tesoro descubierto; mientras que la imposición de una

\footnotetext{
${ }^{87}$ Respecto de la expresión «Caesaris possessio», afirma PULIATTI, Il de iure fisci di Callistrato e il processo fiscale in età severiana, cit., pág. I76 nt. 6, que el término possessio viene utilizado por Calistrato en el sentido de fundo, e indica las posesiones agrarias imperiales. Controvertida resulta la individualización de los bienes indicados con esa expresión, para JONES, «The Aerarium and The Fiscus», en Studies in Roman Governement and Law, Oxford, I960, pág. II3, sólo aquellos que están en la administración de la res privata. Para MITTEIS, Römiches Privatrecht bis auf die Zeit Diokletians, I, cit., pág. 355 nt. I8, sólo los comprendidos en el patrimonium. Para MASI, Ricerche sulla res privata del Princeps, cit., págs. 39 y s., los comprendidos en ambos. Sobre el tema, cfr. BUSACCA, «Qualche osservazione sulle innovazioni introdotte dai divi fratres nel regime giuridico del tesoro», cit., pág. $137 \mathrm{nt}$ I2 y I38 nt. I3.

${ }^{88}$ BUSACCA, «Qualche osservazione sulle innovazioni introdotte dai divi fratres nel regime giuridico del tesoro», cit., págs. 137 y s.

${ }^{89}$ Así, KÜBLER, «S.v. Thesaurus», cit., pág. Io; SPAGNUOLO VIGORITA, Exsecranda pernicies. Delatori e fisco nell'età di Costantino, cit., pág. I75; BUSACCA, «Qualche osservazione sulle innovazioni introdotte dai divi fratres nel regime giuridico del tesoro», cit., pág. 138 .

Cfr. PROVERA, La vindicatio caducorum. Contributo allo studio del proceso fiscale romano, cit., pág. I4I, que limita la sanción por la omisión de denuncia a la pérdida de la mitad del tesoro correspondiente al inventor, por lo que el fisco sólo recibiría la totalidad del tesoro.

DOMÍNGUEZ, «Las pretensiones fiscales sobre los tesoros: Derecho romano y Código civil», cit., pág. 375, limita la sanción a la pérdida de su derecho sobre el hallazgo y al pago de una cantidad equivalente.

Singular aparece la interpretación de HILL, Tresaure Trove in Law and Pratice from the earliest Time to the present Day, cit., pág. 28 nt. 4, que circunscribe la sanción a la pérdida de la parte del tesoro correspondiente al inventor, en cuanto que considera interpoladas las palabras «cum altero tanto».

${ }^{9 \circ}$ PULIATTI, Il de iure fisci di Callistrato e il processo fiscale in età severiana, cit., pág. I79 nt. 68.
} 
pena pecuniaria responde mejor a la necesidad de reprimir la difusión del fenómeno de la clandestinidad y de la ocultación de los descubrimientos.

En cuanto a la sanción por omisión de la denuncia, no puede sólo afectar al locus fiscalis, pues como afirma Busacca ${ }^{91}$ debe aplicarse a todos los casos en los que puedan existir pretensiones del fisco sobre los tesoros. No parece explicable una diversidad de sanciones por el ocultamiento del tesoro descubierto en los loca publica, Caesaris, religiosa y en los monumenta, sobre los cuales existen las mismas pretensiones fiscales que sobre los tesoros descubiertos en los loca fiscalia.

Sobre los tesoros descubiertos en los monumenta, considera Busacca ${ }^{92}$ que es el único caso en el que los divi fratres han hecho valer las pretensiones fiscales sobre los tesoros descubiertos en loca privata, dándole el mismo régimen que a aquellos descubiertos en los loca religiosa, publica, fiscalia y Caesaris. Tal excepción a la no injerencia del fisco sobre tesoros descubiertos en los loca privata, parece inspirada por la exigencia de someter a un régimen jurídico uniforme los tesoros descubiertos en los varios monumentos sepulcrales, en un momento caracterizado por la tendencia a circunscribir la categoría de las res religiosae únicamente a los lugares en los cuales estaban enterrados los cadáveres, con exclusión de los cenotafios, e incluso con la introducción de la prohibición de enterrar pecunia en los monumentos sepulcrales ${ }^{93}$.

Respecto de la falta de mención del tesoro descubierto en los loca sacra, la doctrina ha propuesto distintas explicaciones.

Mayer-Maly ${ }^{94}$ se ha limitado a constatar la ausencia del locus sacer.

Busacca $^{95}$ afirma que la escasa probabilidad de descubrir un tesoro en un locus sacer (es decir consagrado a la divinidad), lleva a pensar que este caso, previsto en la constitución de los divi fratres, haya podido ser omitido por Calistrato.

Impallomeni ${ }^{96}$ excluye que la constitución de los divi fratres mencionase los tesoros descubiertos en los loca sacra, en su opinión continuaba vigente el régimen adrianeo. A esta conclusión llega Impallomeni tras poner en conexión el pasaje de Calistrato con otro de Marciano.

D. 48, I3, 4, 6 (Marcianus, XIV Institutionum): Non fit locus religiosus, ubi thensaurus invenitur: nam et si in monumento inventus fuerit, non quasi religiosus tollitur. Quod enim sepelire quis prohibetur, id religiosum facere non potest: at pecunia sepeliri non potest, ut et mandatis principalibus cavetur.

Para el citado autor, el texto perteneciente a las Instituciones de Marciano, se enmarca en el comentario de la problemática lex Iulia de residuis. Propone la corrección de

\footnotetext{
${ }_{91}$ BUSACCA, «Qualche osservazione sulle innovazioni introdotte dai divi fratres nel regime giuridico del tesoro», cit., págs. 138 y s.

$9^{2}$ BUSACCA, «Qualche osservazione sulle innovazioni introdotte dai divi fratres nel regime giuridico del tesoro», cit., págs. I39 y s.

${ }^{93}$ D. 48, I3, 5, 6 (Marcianus, XIV Institutionum).

${ }^{94}$ MAYER-MALY, «Der Schatzfund in Justinians Institutionen», cit., pág. II4.

${ }^{95}$ BUSACCA, «Qualche osservazione sulle innovazioni introdotte dai divi fratres nel regime giuridico del tesoro», cit., pág. 146 nt. 42.

${ }^{96}$ IMPALLOMENI, «Sulla capacità degli esseri soprannaturali in diritto romano», cit., págs. 4Iy ss.
} 
la parte inicial. En el estado actual, Marciano parece afirmar que el lugar no se hace religioso por el descubrimiento del tesoro, dado que éste no sería a su vez religioso, ni siquiera si se descubre en un monumento funerario. Siguiendo a Mommsen, propone corregir la parte inicial del parágrafo: non fit loco ubi invenitur religiosus thesaurus. Así, el sentido podría ser el siguiente: constituciones imperiales prohíben el enterramiento de dinero con fines funerarios; el dinero sepultado en un lugar religioso, así como aquél ocultado en un monumento, debe considerarse sepultado en contra de lo dispuesto por la ley; por tanto, no podrá considerarse religioso, ni siquiera aunque haya sido realizado por creencias religiosas. Desde este punto de vista, se podría suponer que Marco Aurelio y Lucio Vero en D. 49, I4, 3, Io, más que un derecho del ciudadano sobre las res religiosae, han querido establecer, casi a título de sanción, un derecho fiscal sobre bienes sustraídos de la circulación pública despreciando las disposiciones imperiales; y por ello habrían modificado el régimen del tesoro descubierto en fundo religioso establecido por Adriano.

Por todo ello, continúa Impallomeni ${ }^{97}$, se puede admitir que la regulación adrianea, relativa al tesoro descubierto en un locus sacer, haya permanecido inmutable en época de los Antoninos y de los Severos, cuando escriben Calistrato y Marciano. No es probable que los lugares sagrados fueran comprendidos en los públicos, basándose en la supuesta tesis de que pertenecían al Estado; dada la precedente constitución de Adriano, que había contrapuesto los bienes estatales a aquellos sagrados; una nueva regulación que hubiese pretendido innovar el régimen, presumiblemente habría debido nombrarlos de manera expresa: cuanto menos Calistrato, refiriéndola, no habría podido pasar por alto el eventual cambio. El silencio, por tanto, parece demostrar la aceptación de los principios inspiradores de la precedente disposición legislativa.

La cuota del tesoro correspondiente al fisco, como hemos visto anteriormente, podía actuarse mediante el ejercicio de la vindicatio caducorum en el proceso delatorio ${ }^{98}$.

D. 49, I4, I pr. (Callistratus, I De iure Fisci): Variae causae sunt, ex quibus nuntiatio ad fiscum fieri solet. Aut enim se quis, quod tacite relictum est, profitetur capere non posse vel ab alio praeventus defertur: vel quod mors ab heredibus non vindicatur: vel quod indignus quis heres nuntiatur. Vel quod princeps heres institutus et testamentum sive codicilli subrepti esse nuntiantur: vel quod dicatur quis thensaurum invenisse: vel magni pretii rem minoris ex fisco comparasse: vel praevaricatione fiscum victum esse: vel eum decessisse, qui in capitali crimine esset: vel etiam post mortem aliquem reum esse: vel domum destructam esse: vel ab accusatione recessum: vel rem litigiosam venumdari: vel poenam fisco ex contractu privato deberi: vel adversus leges commissum factum esse.

Por lo que se refiere a nuestro tema, Calistrato menciona, entre los I5 supuestos en los que el fisco puede ejercitar acciones en defensa de sus derechos o tutela de los intereses del Estado, la inventio thensauri como una de las causas por las que se suele hacer denuncia al fisco. De manera que quien omitía la auto denuncia al fisco, perdía la mitad del tesoro que le correspondía más el pago de la pena; en este caso la delatio servía para realizar la pretensión del fisco sobre la totalidad del tesoro más el importe de la cantidad debida como

\footnotetext{
${ }^{97}$ IMPALLOMENI, «Sulla capacità degli esseri soprannaturali in diritto romano», cit., págs. 42 y s.

${ }^{8}$ Así, PROVERA, La vindicatio caducorum. Contributo allo studio del proceso fiscale romano, cit., págs. I27 y ss., I62 y ss.; SPAGNUOLO VIGORITA, Exsecranda pernicies. Delatori e fisco nell'età di Costantino, cit., pág. I75; PULIATTI, Il de iure fisci di Callistrato e il processo fiscale in età severiana, cit., págs. I79 y s.
} 
pena. Spagnuolo Vigorita y Puliatti ${ }^{99}$ califican este supuesto de acción mixta, en cuanto que la actuación del delator se dirige a perseguir tanto una pretensión de naturaleza real como otra obligacional.

El nuevo sistema instaurado por la constitución de los divi fratres, según lo conocemos por el texto de Calistrato, que mantuvo su vigencia hasta la época de Septimio Severo, ha sido valorado de forma distinta por la doctrina con relación al régimen adrianeo.

Lauria, Hill y Scarcella ${ }^{\text {10o }}$, limitan la modificación de los divi fratres a la atribución al fisco de los tesoros descubiertos in locis fiscalibus vel publicis religiosisve aut in monumentis.

Spagnuolo Vigorita y Pessi ${ }^{\text {ror }}$, afirman que aquél que hubiese encontrado un tesoro in locis fiscalibus vel publicis religiosisve, si omitía la auto denuncia, perdía la mitad de lo que le correspondía y se exponía también al pago de una pena, según una decisión de Adriano precisada después por Marco Aurelio y Lucio Vero.

Para De las Heras ${ }^{\text {102 }}$, con el único apoyo de los fragmentos citados, creemos que es difícil establecer si se trata de una modificación parcial o de una aclaración de la norma adrianea, pues caben otras interpretaciones. Por ejemplo, para Ortolán, en las tierras públicas o del César no podía realmente haber un lugar sagrado ni religioso, por lo que la mitad del tesoro descubierto en el mismo debía volver al pueblo o al César en calidad de propietario; esto es lo que nos explica un fragmento mal comprendido del Digesto, en el cual vemos que Marco Aurelio y su hermano Lucio Vero habían atribuido esta parte al fisco.

Orestano $^{\mathrm{ro3}}$ pone el acento en la atribución al fisco de la mitad del tesoro descubierto en cualquier lugar que no pertenezca al descubridor o a un dominus privado. Impallomeni ${ }^{104}$, igualmente, afirma que resulta unificado el régimen del descubrimiento de los bienes públicos, lato sensu, dependientes de distintas administraciones: la mitad del tesoro se adquiere siempre y únicamente por el fisco.

En esta línea, Busacca ${ }^{\text {ros }}$ considera que se ha modificado profundamente el criterio inspirador del régimen adrianeo, especialmente con relación a los tesoros descubiertos en los loca publica y religiosa además de en los monumenta, inspirándose en el principio contrario de atribuir el tesoro al descubridor y reconocer la vindicatio sobre la mitad del mismo al fisco, cuyas pretensiones son hechas valer no iure dominii, sino iure imperii.

${ }^{99}$ SPAGNUOLO VIGORITA, Exsecranda pernicies. Delatori e fisco nell'età di Costantino, cit., págs. I77 y s.; PULIATTI, Il de iure fisci di Callistrato e il processo fiscale in età severiana, cit., pág. I45 nt. 3.

${ }^{100}$ LAURIA, «Dal possessore del tesoro all' 'inventor' (D. 4I.2.3.3.)», cit., pág. 30 nt. 25; HILL, Tresaure Trove in Law and Pratice from the earliest Time to the present Day, cit., págs. 28 y ss.; SCARCELLA, «Una nuova concezione del tesoro alla luce di C. I. IO.I5.I», cit., pág. 2 I 8 nt. 88.

${ }^{\text {ror }}$ SPAGNUOLO VIGORITA, Exsecranda pernicies. Delatori e fisco nell'età di Costantino, cit., pág. I75; PESSI, Situazione economico-sociale e politica finanziaria sotto i Severi, Napoli, I988, pág. I46.

${ }^{\text {ro }}$ DE LAS HERAS, «Adquisición del tesoro en el Fuero de Cuenca: bases romanas y evolución posterior», cit., págs. 62 y ss.

${ }^{103}$ ORESTANO, Il problema delle persone giuridiche in diritto romano, I, cit., págs. 252 y ss.

${ }^{104}$ IMPALLOMENI, «Sulla capacità degli esseri soprannaturali in diritto romano», cit., pág. 4I.

${ }^{105}$ BUSACCA, «Qualche osservazione sulle innovazioni introdotte dai divi fratres nel regime giuridico del tesoro», cit., págs. I45 y s. y I53 nt. 58, pone de relieve el papel fundamental en este proceso innovador adoptado por los juristas miembros del Consilium de estos Emperadores. 
En nuestra opinión, lo primero que conviene destacar es el distinto ámbito de aplicación de ambas constituciones, mientras que la de Adriano se dirige a regular el descubrimiento del tesoro en fundos privados y no privados, la de Marco Aurelio y Lucio Vero únicamente regula las pretensiones fiscales sobre tesoros hallados en fundos no privados. El silencio del tesoro descubierto en los loca sacra podría deberse a que no es objeto de modificación por parte de la constitución de Marco Aurelio y Lucio Vero, es decir, permanece vigente la regulación de Adriano. Además, los divi fratres amplían las pretensiones fiscales a los tesoros descubiertos en los loca religiosa y monumenta. Precisan la pena en caso de falta de denuncia al fisco del tesoro descubierto. Mientras que en el régimen adrianeo, el tesoro descubierto en loco Caesaris, fiscali vel publico se divide la mitad para el descubridor y la otra mitad para el titular del fundo, esto es, el príncipe, la ciudad o el fisco; sin embargo, la constitución de los divi fratres atribuye la mitad del tesoro descubierto en loco fiscali, publico, religioso, in monumentis y loco Caesaris, siempre al fisco. Luego mientras que según Adriano, el fisco participa en el tesoro descubierto en cuanto que es titular del fundo; según Marco Aurelio y Lucio Vero, el fisco participa en el tesoro descubierto con independencia de la titularidad del terreno, por lo que llevaría razón Busacca cuando afirma que sus pretensiones son hechas valer no iure dominii, sino iure imperii. Lo cual no significa que se haya modificado la naturaleza jurídica de la adquisición del fisco, no creemos que sea titular de un derecho de obligación, sino que sigue siendo titular de un derecho real sobre el tesoro descubierto. Por último, destacar la ausencia de la casualidad, silencio que se justificaría por no ser objeto de modificación.

\section{La regulación de Alejandro Severo}

Una ulterior modificación del régimen jurídico de la adquisición del tesoro parece que fue introducida por una constitución del emperador Alejandro Severo, cuyo contenido conocemos a través de un texto de Lampridio, que suscita muchas dudas de interpretación y que parece apuntar una derogación de lo establecido tanto por Adriano como por Marco Aurelio y Lucio Vero, es decir, un restablecimiento de las pretensiones fiscales con carácter general, al menos, en lo que respecta a los tesoros más valiosos.

Vit. Alex. 46, 2: Thesauros reppertos his, qui reppererant, donavit et, si multi essent, addidit his eos, quos in suis habebat officiis.

El inciso «si multi essent», es interpretado por Rotondi, Bonfante o Scarcella ${ }^{\text {ro6 }}$ en el sentido de «los más importantes», Domínguez ${ }^{\mathrm{ro7}}$ habla de «ingentes» y Busacca ${ }^{\mathrm{108}}$ de «mayor valor».

Según el testimonio de Lampridio, Alejandro Severo atribuye el tesoro al descubridor, salvo aquellos más valiosos, en cuyo caso asigna una parte al descubridor y otra parte a algunos funcionarios imperiales.

\footnotetext{
${ }^{106}$ ROTONDI, «I ritrovamenti archeologici e il regime dell'acquisto del tesoro», cit., pág. 32I; BONFANTE, «La vera data di un testo di Calpurnio Siculo e il concetto romano del tesoro», cit., pág. I35; SCARCELLA, «Una nuova concezione del tesoro alla luce di C. I. IO.I5.I», cit., pág. $218 \mathrm{nt} .87$.

${ }^{107}$ DOMÍNGUEZ, «Las pretensiones fiscales sobre los tesoros: Derecho romano y Código civil», cit., pág. 376.

${ }^{108}$ BUSACCA, «Qualche osservazione sulle innovazioni introdotte dai divi fratres nel regime giuridico del tesoro», cit., pág. I54; idem, «s.v. Tesoro», cit., pág. 386.
} 
Bonfante $^{\text {rog }}$ niega la existencia de un cambio, el texto de Lampridio no encuentra correspondencia en los de Calistrato, Ulpiano y Trifonino; en su opinión se trata de una vieja política que se remonta a Nerva, relativa a los tesoros más ingentes, por lo que permanecería en vigor el sistema adrianeo.

Por el contrario, para Busacca ${ }^{\text {IIO }}$ se trata de una verdadera modificación que permanece vigente hasta Diocleciano. Esta modificación, que reintroduce la importancia del descubridor, podría deberse a la influencia de Paulo, que jugó un papel fundamental en el consilium de Alejandro Severo y probablemente fue bajo este Emperador praefectus praetorio.

En opinión de Domínguez ${ }^{\text {III }}$, la facultad de apropiarse de los hallazgos más ingentes, dejando al descubridor la plena propiedad de los menos valiosos, sólo la habría tenido el fisco en aquellos supuestos en que, atendiendo a la legislación vigente, el tesoro le correspondiera. Bajo este prisma, se entiende el empeño de los funcionarios fiscales en averiguar la cuantía y calidad del hallazgo, llegando incluso a la tortura a fin de obtener del denunciante una declaración veraz sobre el descubrimiento. Fuera de tales casos, atendiendo al tenor clarísimo de la legislación adrianea, confirmada por diversas decisiones jurisprudenciales ya mentadas, no hay ninguna base para sostener una atribución al fisco de los tesoros en función de su importancia económica; a fortiori, ni siquiera era preceptiva la denuncia del descubrimiento, sino que el tesoro era adquirido ex lege por el descubridor y, en su caso, el dominus loci, por mitades. Concluye la citada autora que si damos crédito al testimonio de Lampridio, nos encontraríamos con una auténtica novedad respecto de la legislación adrianea, por cuanto el elemento o factor sobre el que giraría la adquisición del tesoro no sería ya el del lugar del descubrimiento, sino el de la importancia o valor del tesoro, siendo por lo demás obligada la denuncia -presumimos- en caso de tesoros ciertamente ingentes. Aceptando esta interpretación, quizás Alejandro Severo sancionó de manera expresa lo que habría sido el auténtico desideratum de sus predecesores.

En nuestra opinión el texto sigue suscitando muchas dudas que parecen quedar sin respuesta. No sabemos a qué lugares se aplica, si a aquellos en los que existen pretensiones fiscales y que fueron determinados por Marco Aurelio y Lucio Vero, o también a los fundos privados, lo que hubiera supuesto una derogación del régimen adrianeo, sin que encontremos una base textual suficiente para afirmarlo. Por otra parte, desconocemos cuál sería la participación del descubridor y de los funcionarios imperiales en el tesoro considerado como valioso. No sabemos cuál es el criterio ni quién tiene la competencia para determinar el valor del tesoro. Igualmente tampoco sabemos si el descubridor tiene siempre la obligación de denuncia al fisco y, en caso contrario, si sigue vigente la sanción establecida por Marco Aurelio y Lucio Vero.

\footnotetext{
${ }^{109}$ BONFANTE, «La vera data di un testo di Calpurnio Siculo e il concetto romano del tesoro», cit., pág. I35.

ro BUSACCA, «Qualche osservazione sulle innovazioni introdotte dai divi fratres nel regime giuridico del tesoro», cit., pág. I54; idem, «S.v. Tesoro», cit., pág. 386.

"II DOMÍNGUEZ, «Las pretensiones fiscales sobre los tesoros: Derecho romano y Código civil», cit., pág. 376.
} 